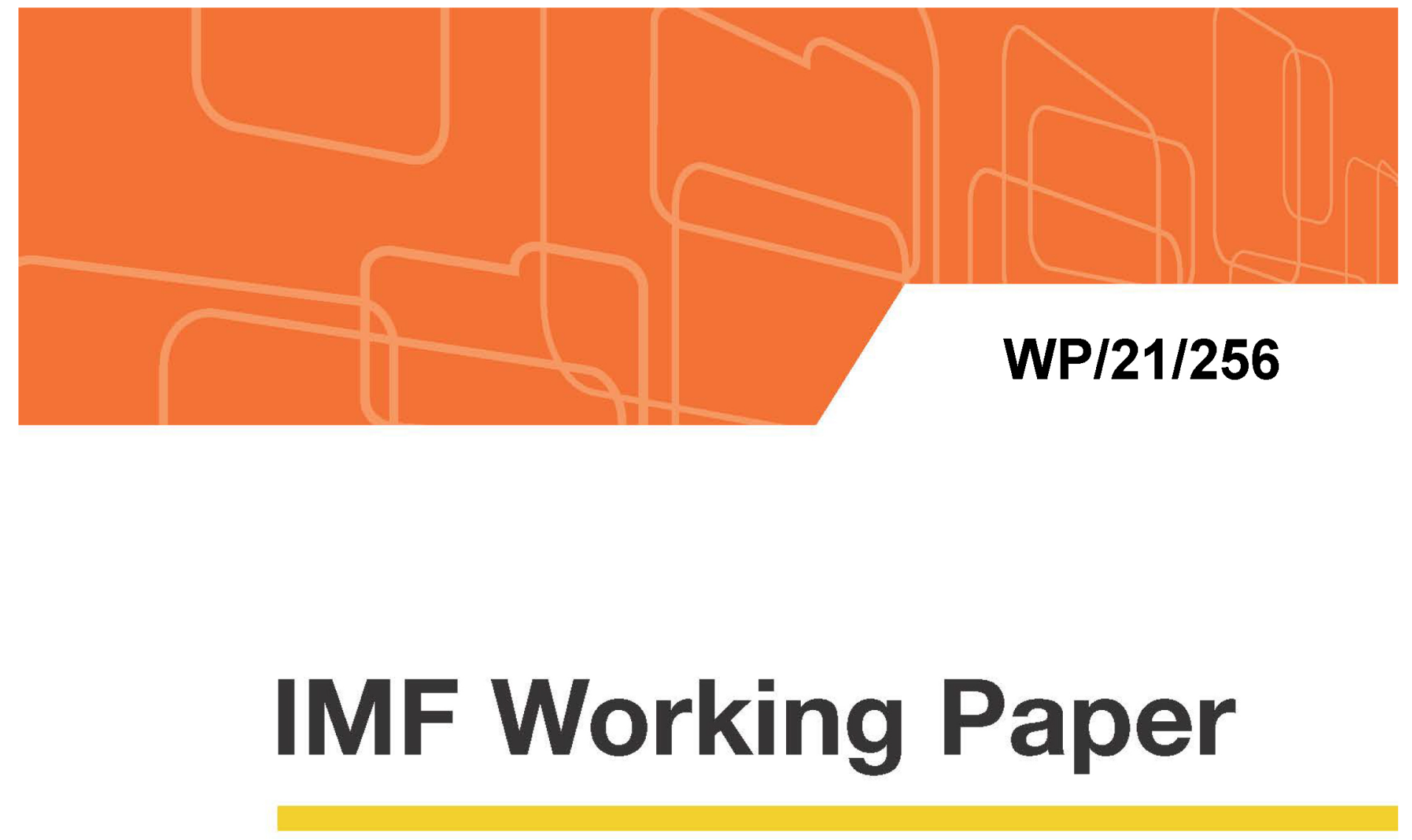

\title{
An Extended Quarterly Projection Model: Credit Cycle, Macrofinancial Linkages and Macroprudential Measures: The Case of the Philippines
}

By Philippe Karam, Mikhail Pranovich and Jan Vlcek

IMF Working Papers describe research in progress by the author(s) and are published to elicit comments and to encourage debate. The views expressed in IMF Working Papers are those of the author(s) and do not necessarily represent the views of the IMF, its Executive Board, or IMF management. 
(C) 2020 International Monetary Fund

$\mathrm{WP} / 21 / 256$

\author{
IMF Working Paper \\ Institute for Capacity Developments
}

An Extended Quarterly Projection Model: Credit Cycle, Macrofinancial Linkages and Macroprudential Measures: The Case of the Philippines ${ }^{1}$

Prepared by Philippe Karam, Mikhail Pranovich and Jan Vlcek

Authorized for distribution by Paul Cashin (ICD)

October 2021

IMF Working Papers describe research in progress by the author(s) and are published to elicit comments and to encourage debate. The views expressed in IMF Working Papers are those of the author(s) and do not necessarily represent the views of the IMF, its Executive Board, or IMF management.

\begin{abstract}
We extend a modern practical Quarterly Projection Model to study credit cycle dynamics and risks, focusing on macrofinancial linkages and the role of macroprudential policy in achieving economic and financial stability. We tailor the model to the Philippines and evaluate the model's properties along several dimensions. The model produces plausible dynamics and sensible forecasts. This along with its simplicity makes it useful for policy analysis. In particular, it should help policymakers understand the quantitative implications of responding to changes in domestic financial conditions, along with other shocks, through the joint use of macroprudential and monetary policies.
\end{abstract}

JEL Classification Numbers: E47, E52, C54

Keywords: Philippines, Forecasting and Policy Analysis, Quarterly Projection Model, Monetary Policy, Macroprudential Policy, Credit Cycle, Leverage Ratio

Authors’ E-Mails: pkaram@imf.org; mpranovich@imf.org; janvlcekatcz@,gmail.com

\footnotetext{
${ }^{1}$ We are grateful for the very helpful comments by the Bangko Sentral ng Pilipinas, MCM and Andy Berg.
} 
Table of Contents

ABSTRACT — $\underline{\underline{2}}$

I. INTRODUCTION —

II. STYLIZED FACTS AND MODEL MOTIVATION___

III. STRUCTURE AND FEATURES OF THE EXTENDED QPM __ 10

A. Credit Cycle Block _

B. Macroprudential Policy Block__ 15

IV. MODEL PARAMETRIZATION AND MODEL PROPERTIES

V. FORECAST EVALUATION _

VI. HISTORICAL INTERPRETATION OF THE DATA USING THE QPM ___ 26

VII. CONCLUSION _ 


\section{INTRODUCTION}

Many Asian countries are seeing rapid financial sector growth. In this context, a number of central banks in the region are interested in developing macroprudential policy knowledge and tools, including better ways of monitoring systemic risk and implementing Basel III requirements.

This paper contributes to this effort by extending a standard New Keynesian (NK) Quarterly Projection Model (QPM) to address macroprudential policy. It incorporates salient financial-real linkages to enable central bank policymakers to analyze the interaction of monetary and macroprudential policies, to better understand side-effects and intertemporal trade-offs and thus better achieve their macroeconomic and financial stability objectives. The primary focus is on the macroprudential policy role in moderating credit growth, in the context of its interaction with monetary policy. ${ }^{2}$

We seek to provide a practical tool for policymakers, in the context of the ongoing policy debate on the role of monetary and macroprudential policies in smoothing business cycles and containing financial vulnerabilities (e.g., IMF (2015); Adrian and Liang (2018)). The paper embeds insights from more complex DSGE models into a simple QPM framework to facilitate structured data analysis, forecasting, and policy analysis. We illustrate the capabilities of the model by customizing it to match key features of the Philippines.

We build on earlier work (Guo et al. (2019)) that analyzed the monetary policy stance and inflation pressures during the 2018 exchange rate stress period with a focus on the impact of exchange rate and trade dynamics. This paper adds two additional blocks, focusing on credit dynamics and macroprudential policy. In a credit cycle block, banks extend credit to firms, considering monetary policy setting and credit risk. A macroprudential policy block models a regulatory authority that sets capital requirements to counter the credit cycle, in the form of a target on the ratio of bank capital to total assets. ${ }^{3}$ The two blocks are linked, because in pricing credit banks levy a spread to meet the prudential target.

This paper draws on an extensive literature on modeling macroprudential policy. Earlier models (Juillard et al. (2008); Benes et al. (2014)) featured financial variables to address macroprudential and financial stability issues. More recently, Adrian et al. (2020a, 2020b, 2020c) developed NK models, highlighting intertemporal tradeoffs between output volatility and

\footnotetext{
${ }^{2}$ This paper is part of a broader ICD project to developing and applying a suite of analytical tools and models to facilitate better macroeconomic forecasting and policy analysis, both for TA and training delivery and for use at the Fund. Related examples include Acosta-Ormaechea and Martinez (2021), Baksa et al. (2020, 2021), Bulir et al. (2021), and Vlcek et al. (2020).

${ }^{3}$ Focusing on cyclical determinants of the use of macroprudential measures, studies have often found that changes in macroprudential policy settings respond mainly to domestic financial variables, especially credit growth (e.g., Aikman et al. (2015); Brandao-Marques et al. (2020); Nier et al. (2020)). The focus of financial stability concerns in the Philippines has been on credit exposure, as the primary risk taken by banks.
} 
financial vulnerability over time, among other complementary work by Alam et al. (2019), Brandao et al. (2020), Chen et al (2020) on macroprudential policy effectiveness and measures. ${ }^{4}$

This paper presents several new features in the modeling framework which, combined, make it uniquely suited to supporting practical forecasting and policy analysis. As a semi-structural "gap" model, it contains enough economic structure to embody key theoretical channels while providing the flexibility to fit the data, including multiple trends, and make reasonable forecasts. Critically, we capture the stance of macroprudential policy through a measurable indicator (the leverage ratio.) ${ }^{5}$ This should allow users to make a direct connection between an actual policy instrument - here a target for the leverage ratio - and the concept of the stance of macroprudential policy, a connection that has been more abstract in the literature. Finally, the model is almost entirely linear to facilitate its use by policymakers, but we kept the nonlinearities that are critical to understanding the dynamics of macroprudential policies in capturing banks' behavior when facing regulatory requirements.

The model is well-suited for policy analysis. Its semi-structural nature does not lend itself to a micro-founded welfare analysis or a mapping from microeconomic distortions to optimal policy regimes. However, it can help users evaluate the effects and tradeoffs of implementing alternative policy strategies, including through their implications for forecasts under various scenarios, in a specific institutional and macroeconomic context. Despite important differences between our approach and others (rooted in DSGE or other empirical methodologies), our results stress as elsewhere, that a joint use of macroprudential and monetary policies help mitigate excessive output and credit fluctuations, in response to changes in domestic financial conditions.

For the model to serve as an operational framework for policy analysis and forecasting, the key challenge is to customize the model to match the data. It should describe reasonably well the dynamics of the key macro variables of the Philippine economy, and policy responses to supply, demand, and financial shocks. We focus on the period since 2000, on the grounds that structural and regime changes render earlier observations much less informative for current policy issues.

The model has satisfactory impulse response functions (IRFs) and is useful for forecasting based on in-sample simulations. In particular, the credit premium is well explained, but the model has a harder time replicating the observed lending rate and credit gap. We quantify the contributions of various exogenous shocks to the dynamics of macro variables of interest and show that domestic and foreign business cycle shocks, along with monetary policy shocks largely account for the credit gap, but the feedback from financial sector shocks to output gap (capturing the business cycle) is relatively minor over the sample period.

\footnotetext{
${ }^{4}$ IMF (2015), and Svensson (2017) emphasized that moving monetary and macroprudential policy in the same direction may have strong adverse effects on output.

${ }^{5}$ Macroprudential policy would in reality affect a number of different dimensions of systemic vulnerabilities, with the concept of a macroprudential stance more properly understood to be multi-dimensional.
} 
The paper is structured as follows. Section II introduces some stylized facts and motivates the model. Section III then explains the model's structure and salient features. Sections IV-VI discuss model parameterization based on an extensive calibration and estimation processes and provide an evaluation of the model's properties along several dimensions - IRFs, counterfactual policy analysis (exploring the effect of active versus passive use of macroprudential policy in particular), in-sample forecasting, interpreting economic developments based on data and statistical filtration, and identifying key structural shocks. Section VII concludes.

\section{Stylized Facts And Model Motivation}

This section highlights the key stylized facts in guiding and motivating this QPM version.

The share of outstanding bank credit to GDP in the Philippines has increased steadily, having almost doubled since 2010 (Figure II.1). The majority of credit has financed production in comparison with a much smaller share of consumer credit. A breakdown of the production loans suggests that the credit has primarily flowed to the real estate, wholesale, manufacturing, and electricity sectors (Figure II.2), accounting for about 60 percent of total. Going forward, we rely on the 'total' amount of credit to firms in the model, considering the short period over which the breakdown is available (2014 onward). ${ }^{6}$

Figure II.1: Outstanding loans (percent of GDP)

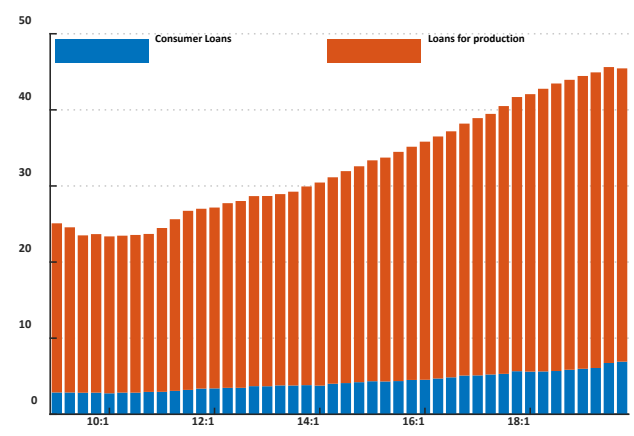

Source: Authors' computation and BSP
Figure II.2: Breakdown of production loans to main sectors (percent of total) (monthly data)

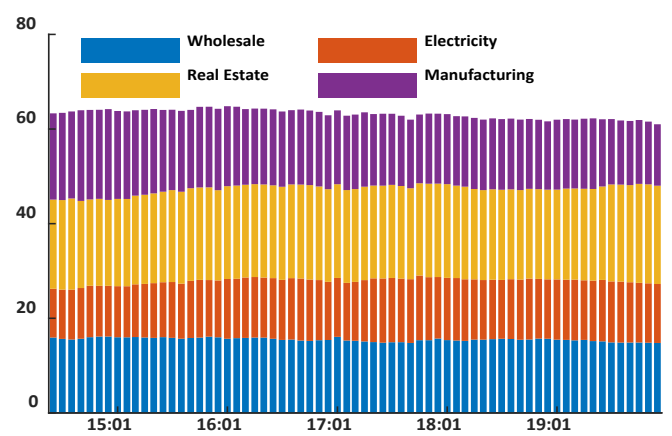

Source: Authors' computation and BSP

Historically, the lending rate for loans to finance production has followed the policy rate closely. A positive spread between the lending rate and the policy rate has existed since 2004, but the dynamics of the rates follow a similar pattern (Figure II.3). This could also indicate that the lending rate is of a relatively short maturity. ${ }^{7}$ The spread is positively correlated with the

\footnotetext{
${ }^{6}$ Credit to households is not included in the model, in view of its small share. Introducing this type of credit would require modeling an asset (mainly housing properties) to serve as collateral.

${ }^{7}$ Data on average maturity of loans is not available. Assuming that an arbitrage-free term structure of interest rates holds, the lending rate is the average of current and expected short-term policy rates over the maturity of loans, adjusted for credit and term premia. If expectations are well-anchored, the expected policy rate converges to the
} 
output gap except in 2009-2010 (Figure II.4) which can be interpreted that in addition to the 'term premium' (because of maturity transformation), the credit rate also includes a 'credit risk premium', which varies with the business cycle.

Figure II.3: Interest rates (percent, per annum)

Figure II.4: Spread (lending rate minus policy rate) (percentage point); output gap (percent, HP filter)
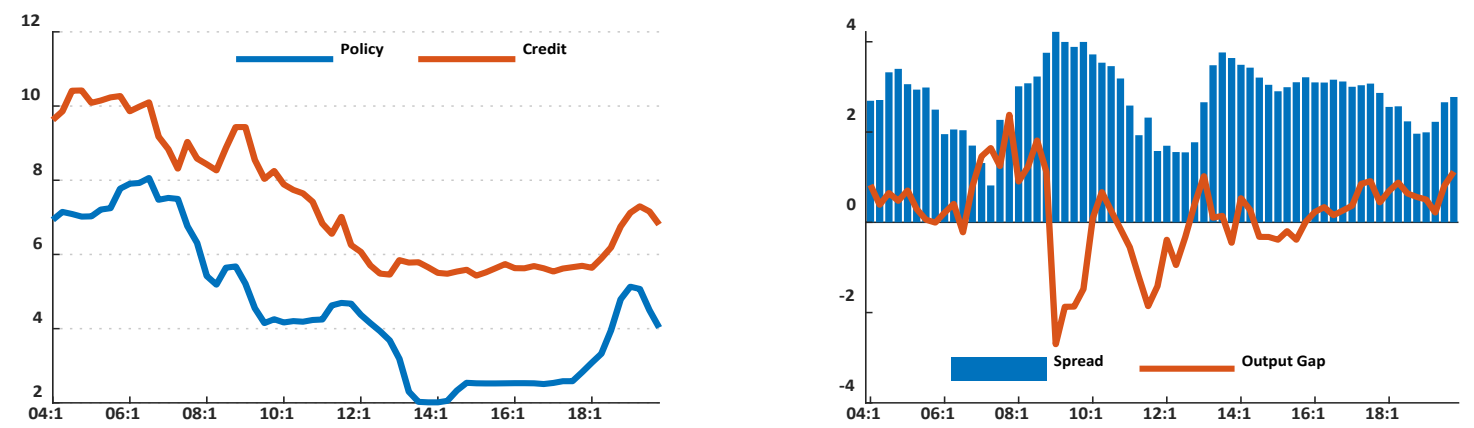

Source: Authors' computation and BSP

Source: Authors' computation and BSP

\section{While the share of outstanding credit to finance production to GDP is not positively correlated with the business cycle, a transformed flow measure yields a positive} correlation. ${ }^{8}$ The data points to a negative correlation when an outstanding (stock) measure of credit is used (Figure II.5). Many models focus on this stock measure when considering countercyclical capital buffer (CCyB), following BIS recommendations. ${ }^{9}$ However, it may be a misleading indicator insofar as it divides a stock of outstanding credit by a flow nominal GDP variable. ${ }^{10}$ To overcome this, outstanding credit is transformed to a flow measure (taking first difference) while also serving as proxy for newly issued bank loans (data on which is not available). As Figure II.6 shows, there is a clear positive correlation between this measure of the flow of credit - in difference terms - with the business cycle (approximated by output gap). The credit gap seems to follow the business cycle with lag, except in 2010-2011 and 2019.

sum of the natural real rate of interest and the inflation target. Similarly, expected premia converge to their longterm levels. As a result, the longer the horizon over which the average of the expected policy rate is calculated, i.e. maturity of loans, the less volatile is the lending rate and vice-versa. A less volatile lending than policy rate (overnight reverse repo rate between the BSP and banks), suggests a lending rate that is of a higher maturity. Considering that the lending rate also co-moves with the policy rate, its maturity may be relatively short, around 1-2 years (an approximation, in line with common observations that credit to finance production is usually up to 2 years).

${ }^{8}$ Simple regression analysis supports this conclusion.

${ }^{9}$ See Basel Committee on Banking Supervision, BCBS (2010).

${ }^{10}$ Byggs and Mayer (2013) point out that GDP is a flow over a period of time, while credit is a stock variable. The stock of credit is a result of previous investment decisions of agents, hence, a measure with inertial features considering that only a smaller part of new loan agreements respond to changing macroeconomic conditions and policy. Therefore, using the stock of credit over GDP as a measure intended to reflect current and expected macroeconomic conditions and policy can be misleading. 
Figure II.5: Gap in the outstanding stock of credit for production (percent of GDP); output gap (percent)

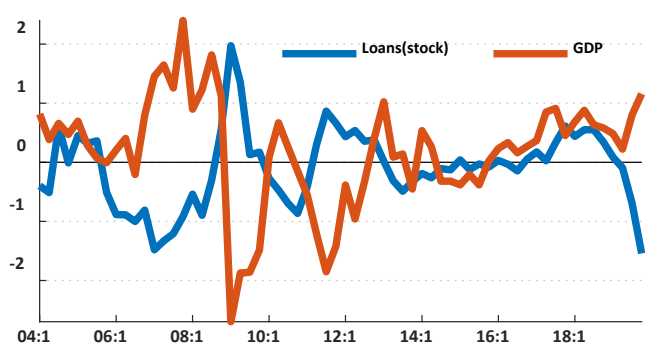

Note: Gaps are computed using HP filter Source: Authors' computation and BSP
Figure II.6: Gap in the flow of credit for production (percent of GDP); output gap (percent) (rhs)

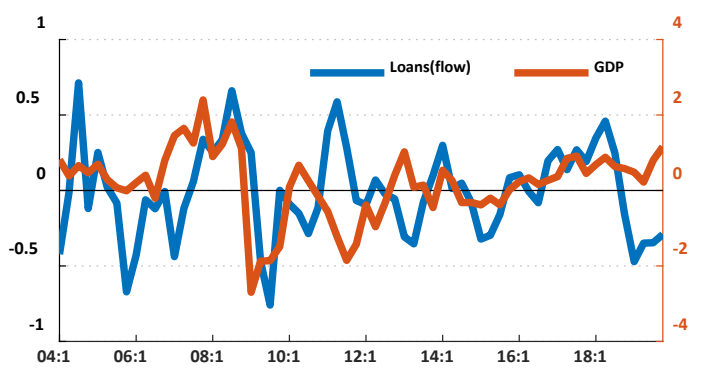

Note: Gaps are computed using HP filter Source: Authors' computation and BSP

\section{In modeling the credit cycle, we extend the standard QPM structure and consider the} composition of banks' balance sheet, profitability of banks, and regulatory requirements (expressed in terms of a leverage ratio in the case of the Philippines, and defined as bank capital-to-total assets, in this paper).

The main component of banks' assets is credit to finance production. We focus on the universal/commercial banking sector $(\mathrm{U} / \mathrm{KB})$ in the Philippines, ${ }^{11}$ where the share of credit to finance production has increased steadily since 2008, reaching almost 50 percent of total bank assets (Figure II.7). The share of financial investment and of financing of real estate purchases (e.g., mortgages) in banks' assets has gradually declined at the margin, and the share of consumer loans held constant at 10 percent. $^{12}$

Figure II.7: U/KBs' bank assets (percent of total assets)
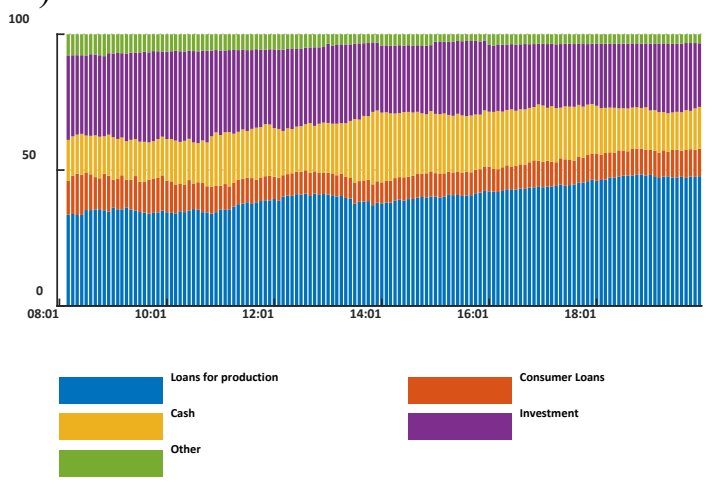

Note: Investment refers to financial and real estate investment. Source: Authors' computation and BSP
Figure II.8: Leverage ratio (defined as bank capital-to-total assets ratio) (percent)

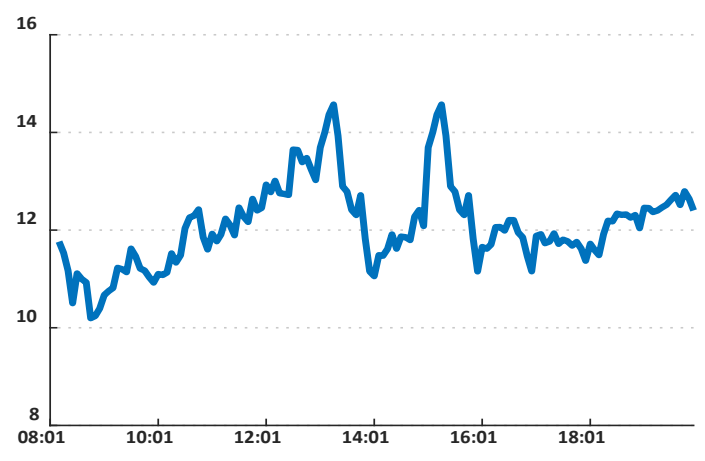

Source: Authors' computation and BSP

\footnotetext{
${ }^{11} \mathrm{U} / \mathrm{KB}$ assets comprised 92.5 percent of the Philippine banking system's total resources as of end-June 2021. The $\mathrm{U} / \mathrm{KBs}$ offer a wide range of banking services among the banking groups.

${ }^{12}$ With the continued expansion in loan portfolio, a closer look highlights some elevated risks observed from banks' exposures particularly to real estate loans and consumer loans (i.e., motor vehicle loans, salary loans and credit cards), although under sustained high bank loan quality with adequate provisioning in place.
} 


\section{Capital requirements address credit risk exposure by banks, and seek to sustain good} quality credit geared to productive use in support of the economy. The leverage ratio is used in the model to express regulatory requirements aimed at moderating credit creation, with implications for lending rate dynamics. It is relatively stable at around 12 percent (Figure II.8), with surges exceeding 14 percent in two episodes. ${ }^{13}$

To better understand its underlying dynamics, we report changes in the leverage ratio, decomposed into the growth of capital and assets (Figure II.9). We observe a first significant decline in the ratio in 2013 and early 2014 which can be attributed to accelerating increases in total assets, unmatched by additional capital accumulation; similarly, in 2016 capital accumulation retreated in 2016 under still growing assets, resulting in a lower ratio. It is worth noting that periods of low capital accumulation have coincided with declines in return on assets (ROA) (Figure II.10), and with increases in the share of non-performing loans (NPLs), disrupting an otherwise declining trend since 2008 (Figure II.11).

\section{Hence, capital accumulation appears to be primarily driven by profit accumulation.} Banks' profitability as measured by the ROA has stabilized since 2016, and the share of NPLs has resumed its declining trend, stabilizing at around 1.5 percent since 2016. In what follows, the ROA is considered as a key variable driving capital accumulation by banks in the model.

\footnotetext{
${ }^{13}$ Basel III leverage ratio requirement was introduced in the Philippines in July 2018, set at 5 percent. The ratio is understood in the BSP regulation as Tier 1 capital over an exposure measure. At the time of preparing the paper, data on Tier 1 capital and the exposure measure - which includes a broader set of on-balance, derivative and offbalance items were not available to us from public sources, hence opting to approximate the macroprudential policy instrument in terms of total capital over credit exposure. Going forward, capitalizing on data availability from BSP, the model could be further customized and operationalized for practical applications for the BSP leverage ratio consistent with the actual regulatory framework. In particular, the macroprudential policy rule for the target leverage ratio (equation 16 below) can be written for the ratio per BSP's definition. Notably, the structure of the rule - that the target ratio is driven by the exposure developments, would not change, making the adjustment to the model a relatively small and straightforward exercise.
} 
Figure II.9: Change of the leverage ratio and its decomposition into growth of capital and assets (percentage point)

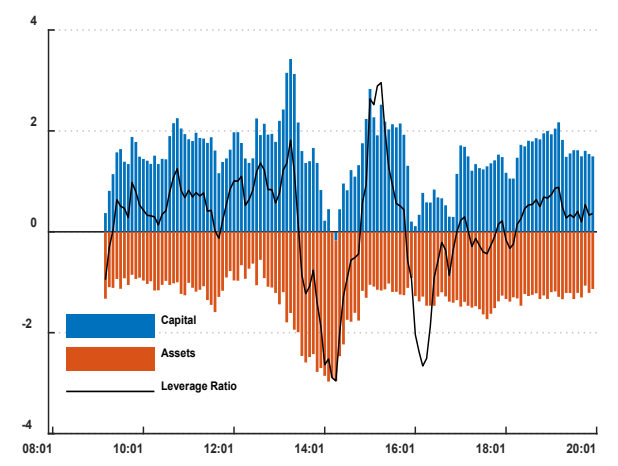

Source: Authors' computation and BSP

Figure II.11: Share of non-performing loans in total assets (percent)

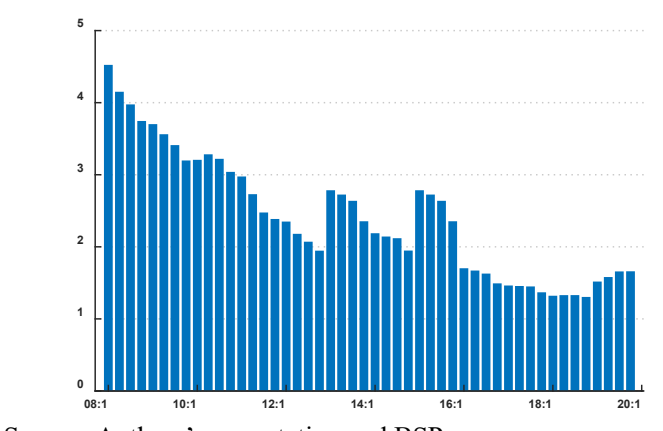

Source: Authors' computation and BSP
Figure II.10: Return on assets (ROA) (percent)

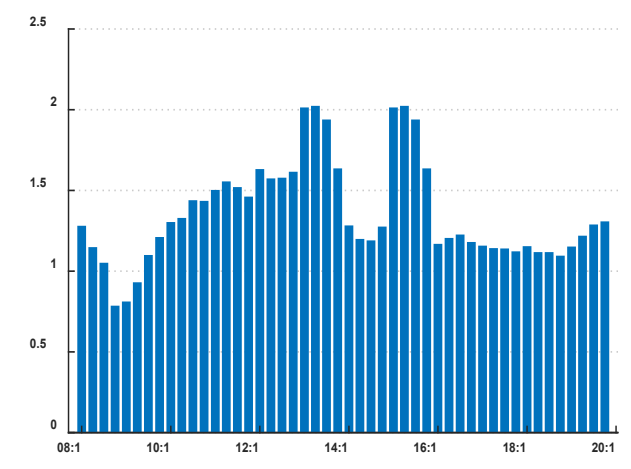

Source: Authors' computation and BSP

\section{StruCture ANd FEATURES OF THE EXTENDED QPM}

The extension of the QPM in this paper will focus on credit behavior, banking sector, and macroprudential policy instrument(s). It starts with a canonical, small open economy, NK structure with nominal and real rigidities and features blocks characterizing the macroeconomic structure of an economy, both easy to use by modelers and comprehensible to policymakers. The model builds on four key behavioral equations, namely: (i) aggregate demand (output gap), (ii) Phillips curve, (iii) uncovered interest rate parity, and (iv) a monetary policy rule. Monetary policy acts through three mechanisms: the interest rate channel, the exchange rate channel, and the expectation channel. The real interest rate affects households and firms via intertemporal decisions, forward-looking monetary policy determines the nominal interest rate, and nominal rigidities are formalized using versions of the NK Phillips curves. The exchange rate ties the domestic and foreign interest rates according to a version of the UIP. ${ }^{14}$ For a full list of model equations and descriptions see Appendix B.

\footnotetext{
${ }^{14}$ A variant of the canonical QPM developed for the Philippines (Guo et al. (2019) includes an external trade block.
} 
The model is in gap form with quarterly data frequency. The gap form means that all real variables are broken down into a gap and a trend (equilibrium). A 'gap' captures movements in a variable driven by business cycle and can be affected by monetary policy in the short run. A 'trend' of a variable is determined by the economy's structural characteristics and it is affected by structural policies, outside the scope of monetary policy. A 'hat' symbol denotes gaps, and a 'bar' denotes the trend. Capital letters in model equations denote the level of a variable, and small letters denote the ratios to GDP or logs (see Appendix A).

Two blocks augment the Philippines' basic QPM. The first, the credit cycle block, incorporates credit dynamics and credit pricing, and the second, the macroprudential policy block, focuses on the banking sector balance sheets and macroprudential policy. The breakdown demonstrates the modular aspects of the model - for instance, the first block is a minimal extension to introduce credit behavior and lending rates in the QPM. Discussing credit risk and mitigating measures in the second block builds on the first, incorporating macroprudential policy and its interaction with monetary (among other potential) policy instruments.

\section{A. Credit Cycle Block}

The credit cycle block assumes that business cycle factors and financial shocks are the main driving forces of the credit cycle. The business cycle position and the price of creditthe lending interest rate-are the main factors. The model also incorporates a feedback channel from the credit cycle to the business cycle. The credit gap block is assumed linear. Risks of credit contract defaults are captured through the credit risk premium, which is driven by the business cycle (the output gap). ${ }^{15}$

In what follows, we focus on key identities and behavioral equations, as well as on interpretation of relevant shocks and premia terms.

Outstanding credit is transformed into a flow of credit. The flow of credit $(N C R)$ is taken as the first difference in the stock of outstanding credit $(C R)$.

$$
N C R_{t}=C R_{t}-C R_{t-1}
$$

This variable approximates the newly issued credit (hence, the NCR acronym) in the model, where negative $N C R$ is interpreted as deleveraging. The ratios in the model are taken with respect to nominal GDP - the ratio of outstanding nominal credit to GDP is denoted by $\mathrm{cr}$, and the flow of nominal credit to GDP by ncr.

The ratio of credit flow to GDP is decomposed into gap and trend (long-term equilibrium) components. The gap part $(\widehat{n c r})$ corresponds to cyclical credit dynamics, and the trend growth $(\overline{n c r})$ captures the structural part of credit:

$$
n c r_{t}=\overline{n c r}_{t}+\widehat{n c r}_{t}
$$

\footnotetext{
${ }^{15}$ In a typical financial accelerator framework (e.g., Bernanke et al. (1999)), stochastic fluctuations in the productivity of investment drive the credit risk premium. This feature is approximated / captured via the link between credit premium and the output gap.
} 
Cyclical demand for credit to finance production - the credit gap — is driven by the business cycle and the cost of loans. In the case of credit to finance production, current and future cash flows sustain the contracted loans (serving as collateral, loosely speaking). The revenue dynamics are approximated by the output gap, $\hat{y}$. Demand for credit is procyclical, rising with (current or expected) economic, production and revenue expansion. The cost of credit is captured by the gap component of the real lending rate $\left(\widehat{r r}^{L}\right)$ where a higher real interest rate gap reduces demand for credit. Thus, the cyclical dynamics of credit are as follows:

$$
\widehat{n c r} r_{t}=\rho^{\widehat{n c r}} \widehat{n c r}_{t-1}+\alpha_{1} \hat{y}_{t}-\alpha_{2} \widehat{r r}_{t}^{L}+\varepsilon_{t}^{n \widehat{n c r}}
$$

$\varepsilon^{\widehat{n c r}}$ is a credit demand shock, which drives credit expansion beyond business cycle considerations.

The trend of credit flow to GDP is determined by long-term country fundamentals. Structural characteristics such as preferences, production structure, and agents' leverage matter. As a simplification, and in line with common practice followed in gap models, the rate of change in the trend variable $(\Delta \overline{n c r})$ follows a simple AR process: ${ }^{16}$

$$
\Delta \overline{n c r}_{t}=\rho^{\overline{n c r}} \Delta \overline{n c r}_{t-1}+\left(1-\rho^{\overline{n c r}}\right) \Delta \overline{n c r} s s+\varepsilon_{t}^{\Delta \overline{n c r}}
$$

$\Delta \overline{n c r}^{s s}$ is the steady-state rate of growth, and $\varepsilon^{\Delta \overline{n c r}}$ is the shock to the equilibrium rate of growth. Because the share of outstanding credit to GDP cannot grow indefinitely, $\Delta \overline{n c r} S S$ is set to zero to reflect that credit increases at the same GDP growth rate in steady state.

In level terms, the trend in credit flow is:

$$
\overline{n c r}_{t}=\overline{n c r}_{t-1}+\frac{\Delta \overline{n c r}_{t}}{4}+\varepsilon_{t}^{\overline{n c r}}
$$

Equation (5) is not an identity as it includes a stochastic term. $\varepsilon^{\overline{n c r}}$ is a shock shifting the level of the trend directly, while $\varepsilon^{\Delta \overline{n c r}}$ in equation (4) is a shock to the trend growth with persistent effects on growth. We introduce both (level and growth) types of shocks to smooth the estimate of the credit gap, on the grounds that the resulting credit gap estimate-purged of the shocks to the level of credit — can be matched more readily with its economic determinants in the data.

The lending rate in the model is linked to the policy interest rate via the unobserved 1-year benchmark rate, consistent with current and expected policy rates. The choice of the 1-year maturity for the benchmark rate is arbitrary, given that data on the exact average maturity of loans is not available. ${ }^{17}$

More specifically, the 1-year benchmark rate $\left(r s_{t}^{1 y}\right)$ is based on the term-structure of the forward policy rates $\left(r s_{t}, \ldots, r s_{t+3}\right)$ over the current quarter and following three quarters. This is a no-arbitrage condition, between investing at the 1-year benchmark rate over the 1-year future

\footnotetext{
${ }^{16}$ The common practice of defining the trend of credit flow-to-GDP in terms of growth, following a simple AR process, seems to be a natural choice considering the increasing credit flow-to-GDP since 2002.

17 This assumption can be subject to further scrutiny and reconsidered if found to be inconsistent with an observed 1 -year rate or with the average maturity of loans.
} 
period, and rolling investment over at quarterly frequency (i.e., four times in the same 1-year period) with the yields from the sequence of the policy rates:

$$
r s_{t}^{1 y}=\rho^{r s^{1 y}} r s_{t-1}^{1 y}+\frac{\left(1-\rho^{r s^{1 y}}\right)\left[r s_{t}+r s_{t+1}+r s_{t+2}+r s_{t+3}\right]}{4}+\operatorname{prem}^{T E R M}+\varepsilon_{t}^{r s^{1 y}}
$$

$\operatorname{prem}^{T E R M}$ is the term premium, and $\varepsilon^{r s^{1 y}}$ is the shock to the benchmark rate which makes it deviate from the 1-year rate implied by the structure of the forward policy rates. ${ }^{18}$ The term premium, assumed to be constant, is the margin banks require for maturity transformation to compensate for the additional uncertainty and illiquidity associated with longer maturities. ${ }^{19}$ The persistence parameter $\rho^{r s^{1 y}}$ controls the passthrough of the policy rate to the 1-year benchmark rate. ${ }^{20}$

The lending rate is observed. It equals the 1-year benchmark rate adjusted for credit risk and regulatory requirements:

$$
r s_{t}^{L}=r s_{t}^{1 Y}+\operatorname{prem}_{t}^{C}+s p_{t}
$$

$\operatorname{prem}_{t}^{C}$ is the credit premium, and $s p_{t}$ is a spread that reflects regulatory requirements imposed on banks. ${ }^{21}$ prem $_{t}^{C}$, is required to account for the probability of borrower default. We assume that the default rate varies inversely with the future business cycle (approximated by the expected output gap) - low during high economic activity, and high in economic downturn. The link to expected output gap shrinks the credit premium during booms (further stimulating credit growth) and increase it during busts. As a result, the dynamics of credit premium amplify the business cycle. The credit premium is also subject to fluctuations in risk appetite in global capital markets, captured by a VIX measure (in log terms) in the model: ${ }^{22}$

$$
\operatorname{prem}_{t}^{C}=\rho^{\text {prem }^{C}} \text { prem }_{t-1}^{C}-\alpha_{3} E_{t} \hat{y}_{t+1}+\alpha_{4} \text { vix }_{t}+\varepsilon_{t}^{\text {prem }^{C}}
$$

\footnotetext{
${ }^{18}$ In the case of the Philippines, the shock can be ignored under an unobserved 1Y rate.

19 The term premium can be potentially changed to be a time-varying process. This would however complicate the model, in linking the time-varying term premium with the business cycle. The challenge lies in distinguishing the unobserved term premium from the unobserved credit premium.

${ }^{20}$ On the possibility of a disconnect between the policy rates and short-term rates, due to varying risk premia and a link to capital flow volatility, more so in emerging and developing economies (EMDEs) than in advanced economies, see Kalemli-Ozcan (2019). Equation (8) below incorporates international market volatility as captured by a VIX measure.

${ }^{21}$ Absent a shock in the lending rate equation, any deviation of the lending rate from the $1 \mathrm{Y}$ rate is interpreted as either a change in the credit premium or a change in the spread driven by regulatory requirements.

${ }^{22}$ The mean is removed from the index to ensure that the premium in equation (8) is zero in steady state.
} 
$\varepsilon_{t}^{\text {prem }^{C}}$ is the shock to the credit premium. The credit premium as defined is assumed to be zero in steady state. ${ }^{23}$

Finally, $s p_{t}$, is the margin banks may impose to fulfill regulatory requirements for capital.

Capital accumulation in the model can be engineered only by retaining profits, with a positive margin or spread, $s p_{t}$, needed to generate such profits.

\section{The real lending rate is decomposed into its gap and trend (natural lending rate) parts.}

The real lending rate $\left(r r^{L}\right)$ is computed based on a Fisher equation:

$$
r r_{t}^{L}=r s_{t}^{L}-E_{t} \pi_{t+1}
$$

and is decomposed into its trend $\left(\overline{r r}^{L}\right)$ and gap $\left(\widehat{r r}^{L}\right)$ components:

$$
r r_{t}^{L}=\overline{r r}_{t}^{L}+\widehat{r r}_{t}^{L}
$$

The equilibrium real lending rate is the natural real rate $(\overline{r r})$, adjusted by the term premium:

$$
\overline{r r}_{t}^{L}=\overline{r r}+\text { prem }^{T E R M}
$$

\section{Feedback from the credit cycle to the business cycle is introduced through the real monetary conditions index as well as the shock to the credit cycle in the aggregate demand equation.}

First, the real monetary condition index ( $\mathrm{mci}$ ), meant to capture the effects of the monetary policy on real economic activity, is amended to allow for the real lending rate gap:

$$
m c i_{t}=b_{4}\left(b_{5} \widehat{r r}_{t}+\left(1-b_{5}\right) \widehat{r r}^{L}\right)+\left(1-b_{4}\right)\left(-\hat{z}_{t}\right)
$$

$\widehat{r r}$ is the short-term real interest (policy) rate gap, and $\hat{z}$ is the real exchange rate gap. Because the lending rate gap is affected by the credit premium, it is akin to a financial condition index as in Adrian et al. (2020b). However, in comparison, this model is more specific with respect to the origin of financial conditions and its transmission channels. ${ }^{24}$

The second feedback channel is incorporated via the credit demand shock featured in the output gap $(\hat{y})$ equation:

\footnotetext{
${ }^{23}$ The treatment of premia in this paper is limited by data availability. Under a general case, the term premium in equation (6) would vary with time, and the credit premium in equation (8) need not be zero in steady state. However, to incorporate these properties in the model, the 1-year benchmark interest rate would need to be observed; lacking data, it is treated as unobserved, limiting our ability to identify term and credit premia. As a result, the constant term premium in equation (6) may also include the non-zero steady state constant level of the credit premium, and part of the time variation in our credit premium estimate could be due to variation in term premium.

${ }^{24}$ Adrian et al. (2020b) postulates that the key linkages between macroeconomic and financial aggregates are via financial conditions (FC). The FC measure, gauging the cost of funding risky projects in the economy, referred to as the price of risk, is driven directly by the volatility of output. In this paper, a similar effect works through a slightly more indirect mechanism. Specifically, monetary policy affects the real economy through the modified mci (equation (12)). This mci contains a real lending term that is a function of the credit premium $\left(\right.$ prem $\left._{t}^{c}\right)$. The credit premium, in turn, varies inversely with the future business cycle (equation (8)) and positively with the regulatory spread $\left(s p_{t}\right)$ (the spread associated with macroprudential measures as described in equation (17)).
} 


$$
\hat{y}_{t}=b_{1} \hat{y}_{t-1}-b_{2} m c i_{t}+b_{3} \hat{y}_{t}^{*}+b_{6} \varepsilon_{t-1}^{\hat{\imath} r}+\varepsilon_{t}^{\hat{y}}
$$

$\hat{y}^{*}$ is the foreign output gap, $\varepsilon^{\widehat{n c r}}$ is the credit gap shock from equation (3), and $\varepsilon^{\hat{y}}$ is the aggregate demand shock. We emphasize that the shock to the credit gap, rather than the credit gap itself, is included in equation (13). This is intended to capture the effect of credit developments on output, whereby the developments themselves are not due to either the business cycle or the cost of credit. The shock enters with a lag to explain the observed data dynamics and to ease identification of unobserved shocks and gaps.

\section{B. Macroprudential Policy Block}

The macroprudential policy block consists of banks and a representative macroprudential authority. The block is non-linear and depends on the structure and underlying relationships from the credit cycle block.

The banking sector extends credit to the economy and accumulate capital. On the asset side of the balance sheet, we focus primarily on credit for production. Capital is featured on the liability side. Other assets (e.g., holding of government bonds, reserves) and liabilities (e.g., deposits) are not modeled explicitly to keep the model tractable. Specifically, these other assets are assumed to have similar properties in terms of the default rate and yields to the extended credit. As a result, the total assets-to-GDP ratio $(t a)$ is modeled as:

$$
t a_{t}=c r_{t}+t a^{\text {wedge }}+\varepsilon_{t}^{t a}
$$

$t a^{\text {wedge }}$ is a constant term used to calibrate the credit-to-GDP ratio to match total assets to GDP, and $\varepsilon^{t a}$ is the shock to the asset side of the banks' balance sheet.

Banks use profits to accumulate capital and pay dividends. The dynamics of the capital-tototal assets ratio $(b c)$ is as follows:

$$
b c_{t}=b c_{t-1} /\left(\frac{T A_{t}}{T A_{t-1}}\right)+\operatorname{roa}_{t}-d i v_{t}+\varepsilon_{t}^{b c}
$$

$T A$ is the level of total assets, roa is the return on total assets (in percent), div is the dividend paid (in percent of total assets), and $\varepsilon^{b c}$ is the shock to capital accumulation.

Two important notes: (i) the equation is non-linear, because the share of capital to total assets is divided by the gross growth of total assets (the term in parentheses); and (ii), there is no newly issued capital as an endogenous strategy to accumulate additional capital — any newly issued capital, if observed in the data, is captured by the $\varepsilon^{b c}$ shock. U/KBs can only accumulate capital from their profits (via roa) and/or by reducing dividend payments (via div).

\section{Banks face regulatory macroprudential requirements set via the ratio of capital to total} assets. The ratio does not use risk-weighted assets and is simply taken to be a leverage ratio. ${ }^{25}$

\footnotetext{
${ }^{25}$ The leverage ratio constitutes a natural choice following Basel III and Basel IV regulations and CCyB recommendations. The leverage ratio definition, consistent with Basel III and Basel IV rules as 'capital to risk-
} 
The target for the leverage ratio $\left(b c^{T A R}\right)$ is set in a countercyclical fashion, with the objective of moderating the credit cycle, according to a simple rule:

$$
b c_{t}^{T A R}=\rho^{b c^{T A R}} b c_{t-1}^{T A R}+\left(1-\rho^{b c^{T A R}}\right)\left(b c_{S S}^{T A R}+\phi \widehat{n c r_{t}}\right)+\varepsilon_{t}^{b c^{T A R}}
$$

$b c_{S S}^{T A R}$ is the steady state level of the leverage ratio, $\widehat{n c r}$ is the credit gap for newly issued loans, $\rho^{b c^{T A R}}$ denotes the degree of persistency in setting the instrument, and $\varepsilon^{b c^{T A R}}$ is the shock to the target level. $\phi$ indexes the strength of policy countercyclicality.

Equation (16) simply assumes that the current level of the target for the leverage ratio is set by a relevant authority. In reality, the target for capital requirements in the Philippines is announced well in advance to provide banks time to accumulate additional capital, though it can be relaxed on short notice if necessary in case of banking system stress. The precise modeling of such a behavior when setting the capital requirements would call for a non-linear function. For tractability, we assume the macroprudential authority follows equation (16). We thus implicitly assume that changes to capital requirements - the actual instrument for the implementation of macroprudential policy in the Philippines-are applied consistent with this rule. ${ }^{26}$

\section{When accumulating capital, banks adjust the lending rate, the lending margin, and} dividend payoffs. Banks increase their lending margins, and hold off on paying dividends, if the leverage ratio drops below target.

Thus, the margin or spread $\left(s p_{t}\right)$ in the lending rate equation (7) is adjusted to meet the leverage ratio target:

$$
s p_{t}=f_{o}\left(b c_{t}-b c_{t}^{T A R}\right)+\varepsilon_{t}^{s p}
$$

$f_{0}$ is a non-linear function, and $\varepsilon^{s p}$ is the shock to the margin. $f_{0}$ is a Gaussian error function calibrated so the margin is zero if the leverage ratio is above target, and is positive and increasing, rising faster the further the leverage drops below the target.

The dividend payoff as a share to total assets $\left(d i v_{t}\right)$ also adjusts to meet the leverage ratio target:

$$
d i v_{t}=f_{1}\left(b c_{t}-b c_{t}^{T A R}\right)+\varepsilon_{t}^{d i v}
$$

$f_{1}$ is a non-linear function, and $\varepsilon^{d i v}$ is the shock to the dividend payoff. $f_{1}$ is a Gaussian error function which sets the dividend payoff to zero if the leverage ratio falls below the target, and is positive and increasing the higher the leverage rises above target.

weighted assets' is used, however without risk-weighing, because data on risk weights for U/KB assets is not available. Not to be confused with an inverse definition in financial economics, with capital in the denominator (i.e., assets/capital or debt/capital). To mention, the target ratio is not novel, backed by Basel's regulatory reforms regarding capital adequacy requirements - Basel IV has introduced a requirement in term of a leverage ratio (defined as the lower limit) expected to come in practice with Basel IV implementation.

${ }^{26}$ This rule for the leverage target is broadly in line with BCBS's suggestions in setting a CCyB (see BCBS (2010)), with the proviso that we do not model the early announcement of the future leverage ratio target. 
The return on assets is determined by the spread between the lending and the policy rate. The lending rate can be a proxy for the yield on assets, and the policy rate can be considered as a cost on the liability side which covers bank deposits or lending from the central bank to banks. $\operatorname{cost}^{a d j}$ is a constant allowing to shift the return on assets to match the data:

$$
r o a_{t}=\frac{r s_{t}^{L}-r s_{t}}{4}+\operatorname{cost}^{a d j}+\varepsilon_{t}^{r o a}
$$

\section{Model Parametrization and Model Properties}

The structure of equations and their parametrization determine the model properties. This section starts with model parametrization, followed by a discussion of the dynamic properties of the model to demonstrate the implications of introducing new blocks in model.

\section{Model Parameterization}

We employ an eclectic and flexible approach to parameterization, as is usually the case for core models used in Forecasting and Policy Analysis Systems (FPAS). This allows us to blend direct evidence from the data, empirical results from other studies, and prior judgments on the model's behavior. This helps balance the need to use the model as a story-telling devicewhich calls for plausible IRFs - with its ability to match the data and produce good forecasts. In sum, we seek to ensure that the model has sensible properties, inspired by economic theory and judged by empirical evidence.

\section{The parameterization of the business cycle part of the model relies on the similar} calibration exercise in Guo et al. (2019). The calibrated values for selected parameters are listed in Appendix C.

A mix of Bayesian estimation and calibration is used in setting parameter values related to the (expanded) credit cycle and macroprudential policy blocks. The list of parameters in these blocks, along with other newly introduced parameters in the rest of the model, is reported in Table IV.1 and Appendix C. In economizing on parameter estimation-necessary given the complexity of model relative to the availability of data - we separate parameters into two groups. The first group includes calibrated parameters: they determine the steady-state of the model and those in non-structural equations. The calibration of steady state parameters reflected either the target level of variables or historical data averages. ${ }^{27}$ The parameters in non-structural equations, mainly for trends, are set to achieve a gradual adjustment or smooth dynamics of model variables towards their steady states. We opted to calibrate rather than estimate parameters in this group, as they determine the dynamics of unobserved variables.

A second group of parameters are estimated using the model and the data. This consists of parameters featured in the structural equations in the new blocks or in the extended business cycle part of the model. Estimation of this complex system is challenging. Specifically, some parameters may exhibit weak identification, where a change of a particular parameter would not

\footnotetext{
${ }^{27}$ Any estimation of these parameter would naturally lead to the historical average.
} 
lead to a substantial change in the model likelihood. Other parameters may be difficult to distinguish from each other because they have similar implications for model properties. ${ }^{28}$ In order to address some of these issues, a test based on a Fisher information matrix (see Andrle (2012)) was conducted to identify groups of parameters that can be estimated simultaneously. ${ }^{29}$ We find evidence that only $\rho_{1}, \alpha_{1}, \alpha_{2}, \rho_{4}$, and $\alpha_{3}$ can be estimated simultaneously (see Appendix D for details). Other parameters in the second group are calibrated to ensure reasonable dynamic properties of the model. Finally, the rule for setting the leverage target is calibrated. The calibration of steady-state level of the leverage ratio is ad-hoc, but because $\mathrm{U} / \mathrm{KBs}$ usually hold a buffer above the regulatory requirements to avoid a penalty and stigmatization, we set the target below the historical observations of the leverage ratio. The choice of persistence and responsiveness to the credit gap are selected to match the data. ${ }^{30}$

Finally, the standard deviations of shocks are generally calibrated, unless indicated as estimated. This is done carefully to get reasonable dynamics of gaps and trends as revealed when the calibrated model is applied to filter the historical data.

Table IV.1: Model parameters related to credit and macroprudential instrument blocks

\begin{tabular}{|c|c|c|c|c|c|}
\hline Parameter & Value & Parametrization method & Parameter & Value & Parametrization method \\
\hline \multicolumn{3}{|c|}{ Demand for credit - equation (3) } & \multicolumn{3}{|c|}{ Credit premium-equation (7) } \\
\hline$\rho_{1}$ & 0.5 & Bayesian estimation & $\rho_{4}$ & 0.8 & Bayesian estimation \\
\hline$\alpha_{1}$ & 0.14 & Bayesian estimation & $\alpha_{3}$ & 0.2 & Bayesian estimation \\
\hline$\alpha_{2}$ & 0.12 & Bayesian estimation & $\alpha_{4}$ & 0.001 & Calibration \\
\hline \multicolumn{3}{|c|}{ Credit growth trend - equation (4) } & \multicolumn{3}{|c|}{ Real monetary condition index - equation (12) } \\
\hline$\rho_{2}$ & 0.75 & Calibration & $b_{4}$ & 0.7 & Calibration \\
\hline$\Delta \overline{n c r}^{s s}$ & 0 & Calibration & $b_{5}$ & 0.5 & Calibration \\
\hline \multicolumn{3}{|c|}{$1 Y$ rate - equation (5) } & \multicolumn{3}{|c|}{ Aggregate demand } \\
\hline$\rho_{3}$ & 0.5 & Calibration & $b_{1}$ & 0.6 & Calibration \\
\hline \multicolumn{3}{|c|}{ Target for the leverage ratio - equation (16) } & $b_{2}$ & 0.2 & Calibration \\
\hline$\rho_{5}$ & 0.975 & Calibration & $b_{3}$ & 0.6 & Calibration \\
\hline$b c_{S S}^{T A R}$ & 11 & Calibration & $b_{6}$ & 0.25 & Calibration \\
\hline$\phi$ & 0.5 & Calibration & & & \\
\hline
\end{tabular}

Source: Authors' computations

\section{Model Properties-Analyzing IRFs}

We focus on the impulse response to shocks originating in the financial system. The new credit and macro-prudential blocks do not alter the impulse responses to common business cycle

\footnotetext{
${ }^{28}$ See Appendix D for discussion of identification issues. The Appendix shows that $b_{5}$ and $\rho_{4}$ are difficult to distinguish from other parameters in the model, for example.

${ }^{29}$ The Fisher matrix is the property of the model and is not related to the data.

${ }^{30}$ When applying the model in a practical policy context, the rule for the leverage target may need to be recalibrated to better reflect current preferences of policy makers and not necessarily the historical data.
} 
shocks in Guo et al. 2019, though they do allow the model to track the response of credit. ${ }^{31}$ In particular, the lending rate depends only on the expected path of the policy interest rate. By extending the paper to include a leverage constraint, we examine the responses to shocks originating in the financial system and how they are conditioned on macroprudential policy. In this case, the response of the lending rate (and real lending rate gap), incorporates more than just an effect of the policy rate, as we will see. In what follows, all shocks are 1 percent in magnitude and are unexpected.

\section{Credit demand shock}

A positive shock to demand for credit—measured as a shock to the credit gap-captures an increase in demand for credit above trend and after controlling for the business cycle position and cost of credit. Such a shock is of primary interest because it reflects the case of excessive growth of credit which may threaten financial stability.

In response, the macroprudential authority raises the required leverage ratio, in order to moderate credit growth and thus safeguard bank soundness and resilience (Figure IV.1) ${ }^{32}$ In order to meet the higher required leverage ratio, banks accumulate capital. ${ }^{33}$

At the same time, a higher demand for credit boosts the asset side of bank balance sheets. ${ }^{34}$ For a given level of bank capital, the leverage ratio drops below the target, ceteris paribus, as shown in the initial drop in Figure IV.1. In response, banks boost capital by increasing their lending margins to generate additional profit, consistent with equation (17)-namely $f_{o}\left(b c_{t}-b c_{t}^{T A R}\right)>$ 0 , under $b c_{t}-b c_{t}^{T A R}<0$. As a result, the lending rate rises significantly. Additionally, banks cut dividend payments to zero, consistent with equation (18), in which $f_{1}\left(b c_{t}-b c_{t}^{T A R}\right)$ is close to zero under $b c_{t}-b c_{t}^{T A R}<0 .{ }^{35}$ Both measures, raising margin and cutting dividends, help banks raise capital to meet the higher leverage ratio target. ${ }^{36}$

To show the role of macroprudential policy in mitigating the credit cycle and its implications on monetary policy, we conduct a counterfactual exercise in which the leverage ratio target is kept unchanged. Figure IV.2 compares the case of an active countercyclical macroprudential policy — raising the leverage ratio in response to the credit

\footnotetext{
${ }^{31}$ Common business cycle shocks refer to demand, cost push (supply), exchange rate, and monetary policy shocks.

${ }^{32}$ The shock to the credit gap is implemented as a shock minus control. Hence, all variables are reported as deviations from the steady state.

${ }^{33}$ We clarify that the adjustments to the required leverage ratio are hypothetical in nature. The BSP has not revised the 5 percent minimum Basel III leverage ratio or the 5 percent total capital to total assets ratio under the Prompt Corrective Action (in case of non-compliance) since their adoption.

${ }^{34}$ Bank lending is demand determined. We assume there is no supply constraint in that banks supply loans to meet the demand for loans by customers.

${ }^{35}$ Deviations of dividend payoffs from zero in the simulation are very small possibly due to numerical errors generated by the non-linear model simulation.

${ }^{36}$ The dynamics of the leverage ratio target follows model equation (16) and can be modified by calibration of the parameters.
} 
boom (depicted by solid lines) — with the case of keeping the ratio unchanged (depicted by dotted lines). The results show that raising the leverage ratio induces a larger increase in the lending rate compared to an unchanged leverage ratio, playing a visible role in mitigating the credit boom. ${ }^{37}$ Furthermore monetary policy tightening is milder, aided by the active role of macroprudential policy. ${ }^{38}$

Figure IV.1: Credit demand shock
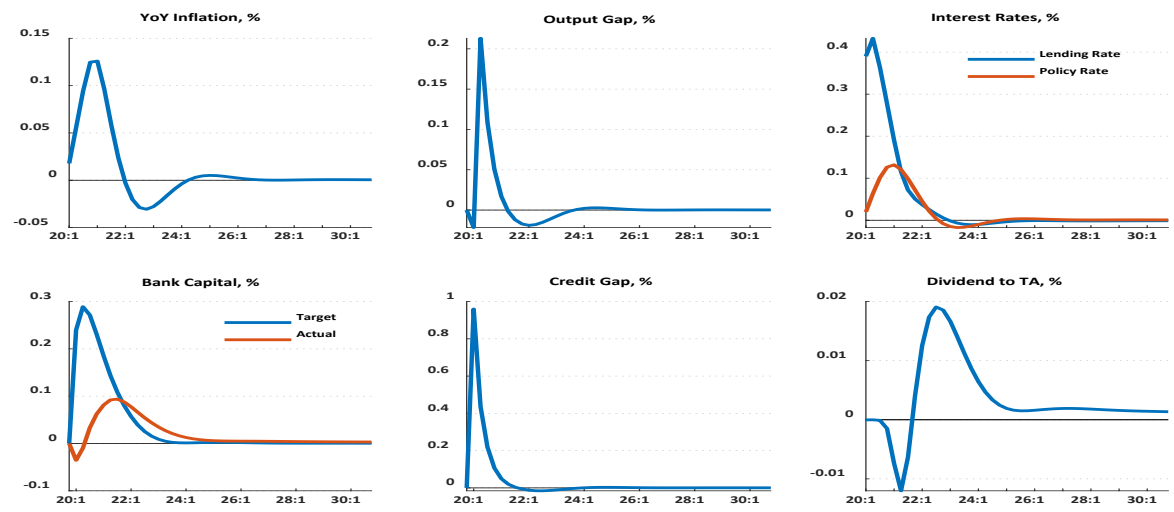

Source: Authors' computation

Figure IV.2: Credit demand shock - counterfactual exercise
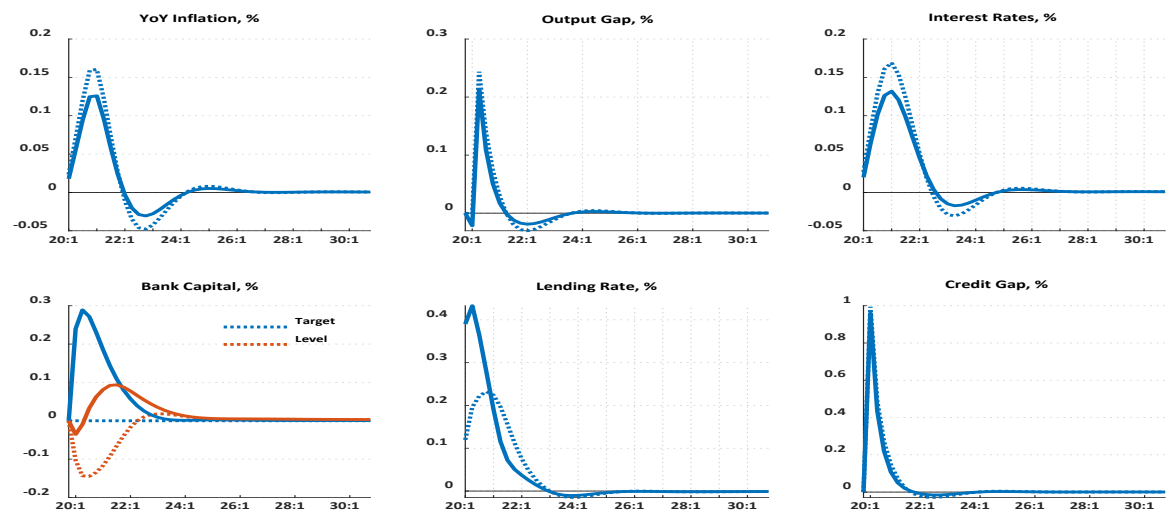

Note: Solid lines capture the active macroprudential policy of adjusting the leverage ratio target; dotted lines capture the counterfactual of an unchanged leverage ratio target.

Source: Authors' computation

\footnotetext{
${ }^{37}$ A leverage target plays a stabilization role mitigating the credit cycle by preventing a significant decline of capital in banks relative to their assets. Hence, imposing the leverage ratio requirement is stabilizing and countercyclical in the case of demand booms even without shifting its level.

${ }^{38}$ In the model's standard Taylor Rule formulation, monetary policy reacts strictly to inflation deviations from target and to output gap, and does not directly to credit growth. Monetary policy tightening nonetheless follows a credit demand shock because the higher credit growth boosts demand and hence the output gap and eventually inflation, triggering a hike in the policy interest rate.
} 


\section{Bank profitability shocks}

The non-linearity in the macroprudential block of the model is key to capturing banks' behavior when facing regulatory requirements.

In the face of a sudden drop of bank profits, the regulatory authority cuts the leverage ratio target in order to ease stress in banks by allowing them to use accumulated buffers

(following the reaction function specified in equation (16)). Figure IV.3 highlights the case of a sudden drop in banks' profits, driven for example by an increase in default rates on earlier loans. ${ }^{39}$ Given the calibration of the macroprudential reaction function, the leverage ratio drops below the lowered target, triggering banks to withhold dividend payments and increase their lending margin (similar to the response to the credit shock, in this respect). The higher lending rate reduces demand for credit, generating a slowdown in economic activity and a negative output gap. Inflation drops below target and monetary policy becomes accommodative. This shock is characterized by the movement of policy and the lending rates in opposite direction.

To demonstrate the countercyclical effects of an active macroprudential policy, a counterfactual exercise keeps the leverage ratio target unchanged (Figure IV.4). We observe that the stress in the banking sector (under a negative profitability shock) is higher with this passive macroprudential policy. This is evident through the shallower drop in the actual leverage ratio; more adverse effects on credit creation; and bigger declines in the output gap, compared to an active policy. Monetary policy accommodation of the adverse shock is correspondingly higher under the active macroprudential policy scenario.

\footnotetext{
${ }^{39}$ The decline is assumed to be gradual, following equation (16). However, in reality macroprudential policy would presumably reduce the target swiftly while its buildup is typically gradual.
} 
Figure IV.3: Negative shock to banks' profits
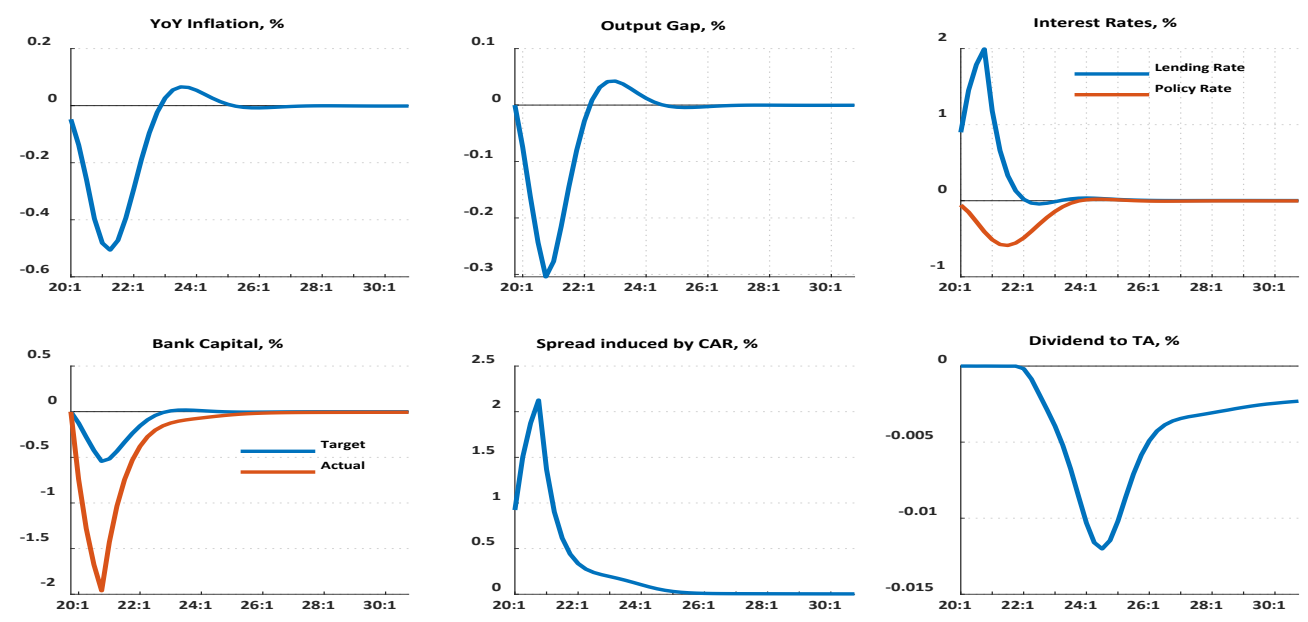

Source: Authors' computation

Figure IV.4: Negative shock to banks' profits - counterfactual exercise
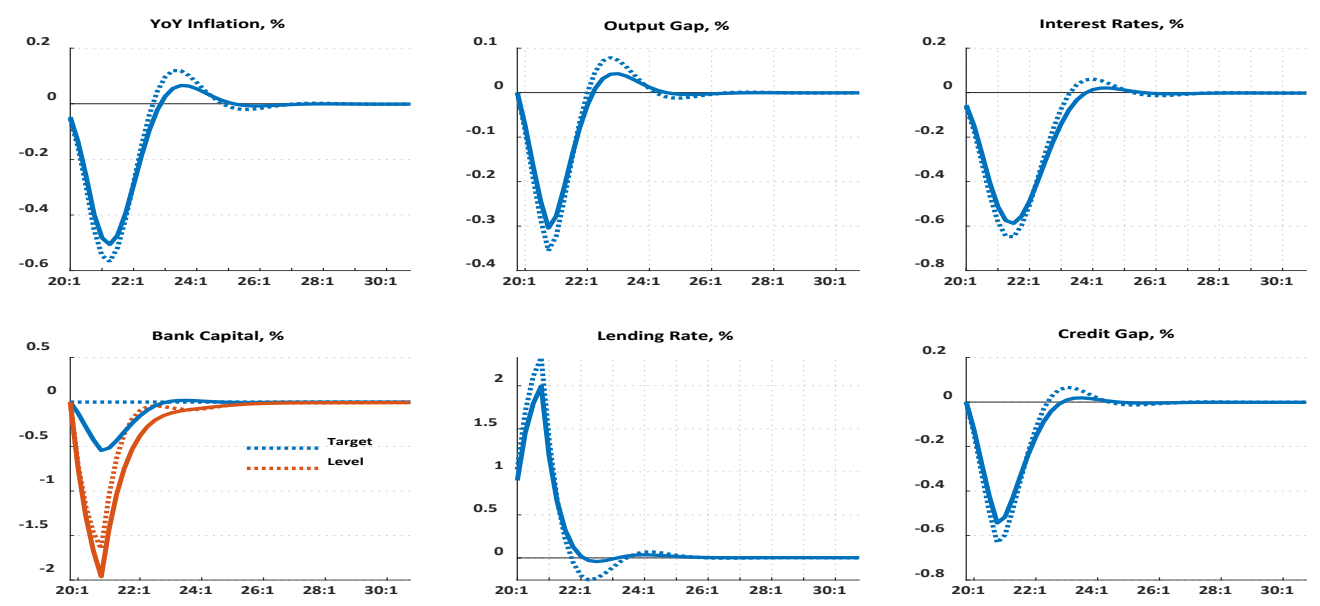

Note: Solid lines capture the active macroprudential policy of adjusting the leverage ratio target; dotted lines capture the counterfactual of an unchanged leverage ratio target

Source: Authors' computation

\section{A positive shock to banks' income (Figure IV.5) may not require macroprudential policy} to react, in contrast to the adverse shock to bank profitability. Unless macroprudential policy seeks to build additional capital buffers, banks are allowed to use extra profits to pay dividends - under higher income, banks' leverage ratio increases above target. Under excess capital $\left(b c_{t}-b c_{t}^{T A R}>0\right)$, the spread (equation 17) becomes zero: $f_{o}\left(b c_{t}-b c_{t}^{T A R}\right)=0$, and banks use profits to pay dividends equation (18): $f_{1}\left(b c_{t}-b c_{t}^{T A R}\right)>0$. The lending rate does not change and consequently the output gap is zero leaving inflation at the target. 
Figure IV.5: Positive shock to banks' profits
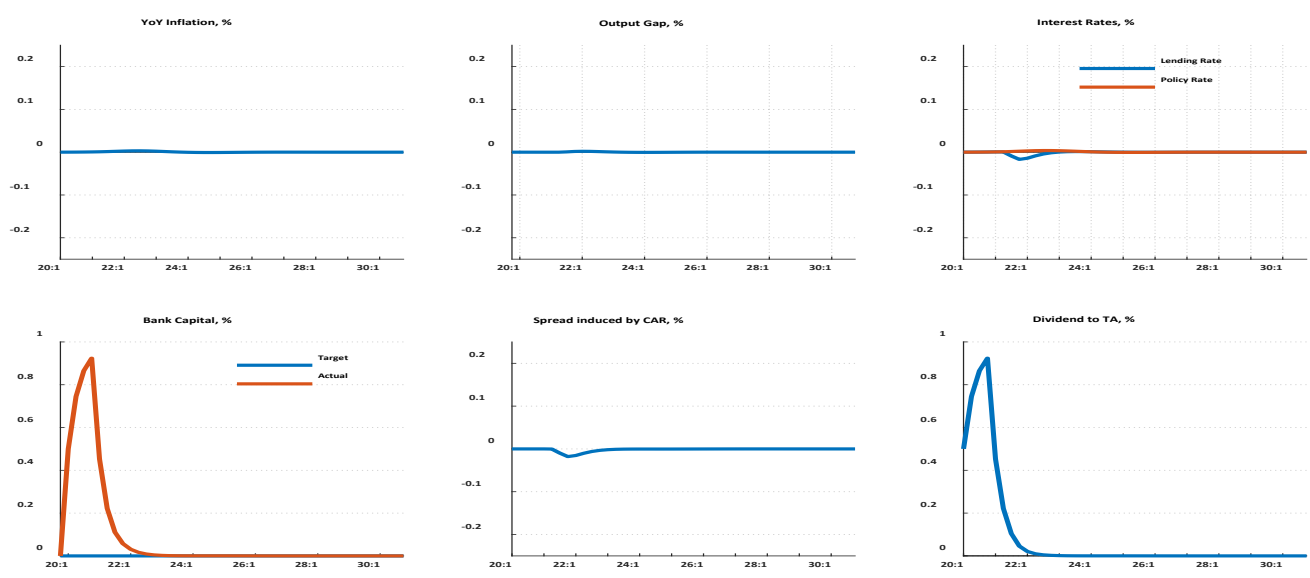

Source: Authors' computation

\section{We draw the following conclusions from these simulations:}

- The macroprudential authority needs to react based on an understanding of the underlying shock. For example, a drop in the leverage ratio below target because of an excessive credit boom requires a different response to the case of an adverse shock to (bank) profitability. This underlines the important role of the model in identifying underlying shocks and assessing whether credit growth is excessive or not.

- A countercyclical macroprudential policy could mitigate the need for monetary policy to react, as shown for the cases of excessive credit booms and drop in bank profitability. ${ }^{40}$

- $\quad$ The non-linearities help produce more reasonable dynamics properties. In their absence, the impulse responses would be symmetric and would not be helpful for the regulatory authorities in distinguishing between positive and adverse shocks to profitability. As seen above, such distinction is critical to policymakers to better understand the different implications on banks' behavior, and as a consequence apply the appropriate macroprudential policy responses.

These conclusions are in line with the consensus view in the literature highlighting the call for countercyclical macroprudential policy in the face of endogenous financial sector procyclicality and risk-taking.

\footnotetext{
${ }^{40}$ Note that the monetary policy reaction function itself is unchanged; the macroprudential policy simply buffers the effects of financial shocks, which thus generates smaller macroeconomic disequilibria and thus call for small monetary policy reactions. Considerable literature suggests that monetary policy is often an inefficient and costly tool to address financial stability concerns (e.g., Svensson, 2017, Collard et al., 2017, Brandao-Marques et al., 2020).
} 


\section{Forecast Evaluation}

Having examined the impulse response functions, in this section and the next we subject the parameterized model to a range of further evaluation exercises, illustrating the strengths and weaknesses of the model for forecasting and policy analysis. These exercises also serve to verify the parametrization.

Here, we examine in-sample forecast accuracy over the sample of 2002Q1-2019Q4. We start from just a quarter before the beginning of the simulation sample (2001Q4) and run a pure model-based forecast for the subsequent six quarters. ${ }^{41}$ We then move one quarter ahead and repeat until we reach 2019Q4, the last period of the simulation. Table V.1 compares root mean square errors (RMSE) of the model-based forecasts with those for a benchmark random walk model. ${ }^{42}$

Table V.1: Model-based forecast versus random walk Root Mean Square Errors (RMSE)

\begin{tabular}{lcccccccccccc}
\hline & & \multicolumn{1}{c}{$2002-2019$} & \multicolumn{6}{c}{$2010-2019$} \\
& $\mathrm{t}+1$ & $\mathrm{t}+2$ & $\mathrm{t}+3$ & $\mathrm{t}+4$ & $\mathrm{t}+5$ & $\mathrm{t}+6$ & $\mathrm{t}+1$ & $\mathrm{t}+2$ & $\mathrm{t}+3$ & $\mathrm{t}+4$ & $\mathrm{t}+5$ & $\mathrm{t}+6$ \\
\hline Business Cycle Block & & & & & & & & & & & & \\
Inflation, y-o-y & 0.5 & 0.6 & 0.7 & 0.8 & 0.9 & 0.9 & 0.6 & 0.7 & 0.8 & 0.8 & 0.7 & 0.6 \\
Policy interest rate & 2.1 & 2.1 & 2.0 & 2.0 & 1.9 & 1.9 & 1.5 & 1.4 & 1.3 & 1.2 & 1.0 & 0.8 \\
Real GDP growth, y-o-y & 0.5 & 0.5 & 0.5 & 0.5 & 0.6 & 0.7 & 0.5 & 0.4 & 0.4 & 0.6 & 0.7 & 0.8 \\
Nom. exchange rate depreciation, & & & & & & & & & & & & \\
y-o-y & 0.6 & 0.6 & 0.5 & 0.5 & 0.5 & 0.5 & 0.5 & 0.4 & 0.4 & 0.5 & 0.5 & 0.6 \\
Output gap & 0.9 & 0.9 & 0.8 & 0.8 & 0.8 & 0.9 & 1.0 & 0.9 & 0.8 & 0.7 & 0.8 & 0.9 \\
Credit block & & & & & & & & & & & & \\
Credit flow/GDP gap & 1.0 & 1.0 & 1.0 & 1.1 & 1.3 & 1.3 & 1.1 & 1.0 & 1.1 & 1.1 & 1.0 & 1.1 \\
Outstanding credit/GDP & 0.8 & 0.8 & 0.7 & 0.7 & 0.7 & 0.6 & 0.6 & 0.6 & 0.6 & 0.6 & 0.6 & 0.5 \\
Lending rate & 1.5 & 1.4 & 1.5 & 1.5 & 1.5 & 1.5 & 2.7 & 1.1 & 1.7 & 1.4 & 1.3 & 1.2 \\
Credit premium & 0.8 & 0.7 & 0.7 & 0.7 & 0.7 & 0.7 & 1.1 & 1.0 & 1.0 & 1.0 & 1.0 & 0.9 \\
\hline
\end{tabular}

Note: A value $<1$ means the model forecast RMSE is lower than the RMSE of random walk, and the opposite for a value $>1$. A value of 1 , means that the RMSEs of the model and random walk are the same.

Source: Authors' computations

These forecasts assume that the following are known: (i) the estimates of unobserved variables for the current quarter (based on information from the entire sample); and (ii) all external variables over the forecasting horizon. Additionally, because macroprudential authority was not setting the leverage ratio in the historical sample we use, we assume that the spread, leverage ratio, and ROAs are observed. Furthermore, because no macroprudential measures have been applied in the historical sample we use, we only test the forecasting performance of the model's credit block, but not its macroprudential policy block.

\footnotetext{
${ }^{41}$ A forecast is considered as a pure model-model based forecast if there are no expert judgments and no changes of the model's parameters and structure.

${ }^{42}$ In practice, forecast accuracy would be further assessed in a true out-of-sample fashion through assessment of results from the model's ongoing use. In this context judgment would have modified the model's forecasts, and the ex-post evaluation could separately assess the role of this judgment.
} 
A word of caution: differences between model forecasts and outcomes need to be carefully analyzed. Where they exist, they should not be automatically interpreted as a result of shortcomings in the model's structure or calibration. The forecast is purely based on the model. The differences may also result from policy mistakes, for example temporary deviations of monetary policies (or macroprudential policies if used historically) from model-prescribed stabilization rules.

\section{Overall, Table IV.1 suggests that the model outperforms random walk forecasts for} business cycle variables, with the notable exception of the policy rate, but the evidence on the credit cycle is mixed. We can get a much richer picture of the credit cycle forecasts by examining the quarter-by-quarter sequence of forecasts compared to outcomes (Figure V.2). Consistent with Table V.1, these results suggest that the model fails to predict the evolution of the policy rate (but with noted improvement post 2010), matches the credit premium well, falls short of replicating the lending rate, and produces mixed results for the credit gap.

The forecasted policy rate is much more volatile than the actual rate (Figure V.1). According to the policy rule (Appendix A, equation B.13), the arrival of the global financial crisis called for a negative interest rate, pushing down the forecast of the $1 \mathrm{Y}$ benchmark rate and the lending rate accordingly. Similarly, during 2015-2016, the in-sample simulations imply a counterfactual drop in the policy rate. The predicted policy rate peaks in 2008-2009, a period during which inflation in the Philippines was well above the target and output gap was positive; again, such a peak is not seen in actual data. Overall, the actual policy rate was apparently much less responsive to business cycle factors - notably the inflation rate and the output gap — than assumed in the model. ${ }^{43}$

The in-sample forecasts for the credit premium are fairly similar to the full-sample estimates, particularly prior to the global financial crisis, though they overshoot during 2011-2012 (Figure V.3). The overshooting reflects the elevated VIX suggesting an outflow of capital which increases the credit premium. The high credit premium opens later a negative credit gap which is lower than what is observed in the data (Figure V.2).

\footnotetext{
${ }^{43}$ We could of course recalibrate the policy rule to reflect this observation. We prefer not to because the main point of the model is to support future forecasts and policy-making, and in this context it is useful to reflect the stated intentions of the policymakers, even if past outcomes at times differ from these intentions. Importantly, the forecasts of the policy rate seem to improve after 2010, suggesting that the assumed policy rule may be a better approximation for current purposes.
} 
Figure V.1: Policy rate (percent)

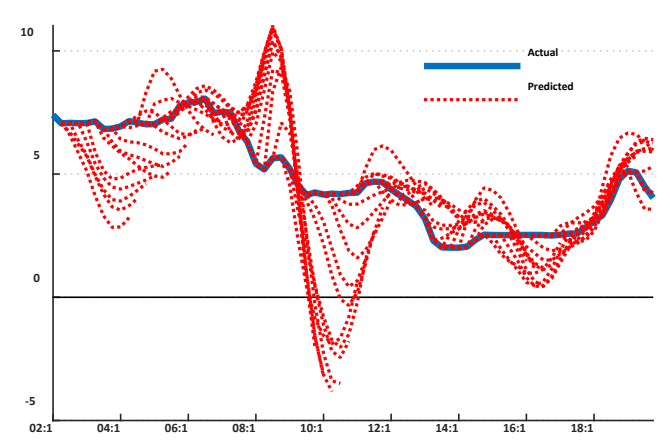

Source: Authors' computation
Figure V.2: Credit gap (percent)

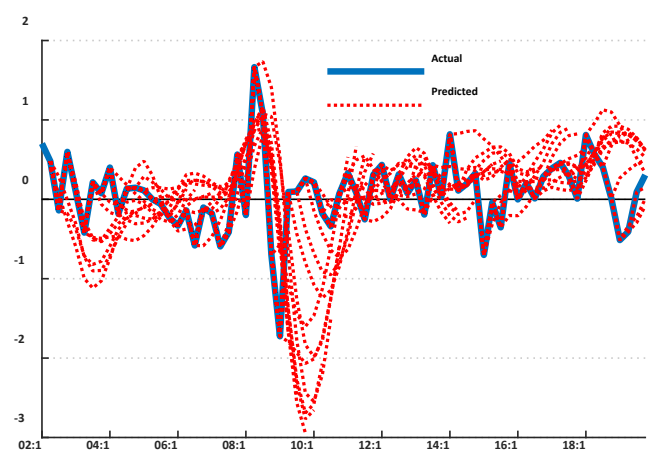

$\underline{\text { Source: Authors' computation }}$

The forecasts of the nominal lending rate appear to be somewhat downward biased throughout the period, except for an upward bias prior to the global financial crisis (Figure V.4). From equation (7), the lending rate equals the sum of the $1 Y$ benchmark rate, the credit premium, and the regulatory margin. Given the assumption, that the term premium and margin (in equations (6) and (7)) are fixed, the policy rate and the credit premium are the only factors which can cause deviations of lending rate forecasts from actual data. As we just saw, the forecast for the credit premium is generally reasonable, hence the forecast bias for the lending rate results from the errors in predicting the policy rate.

\section{Figure V.3: Credit premium (percent)}

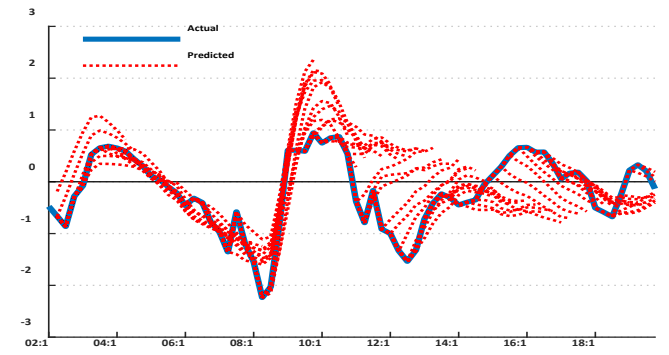

Source: Authors' computation

\section{Figure V.4: Nominal lending rate (percent)}

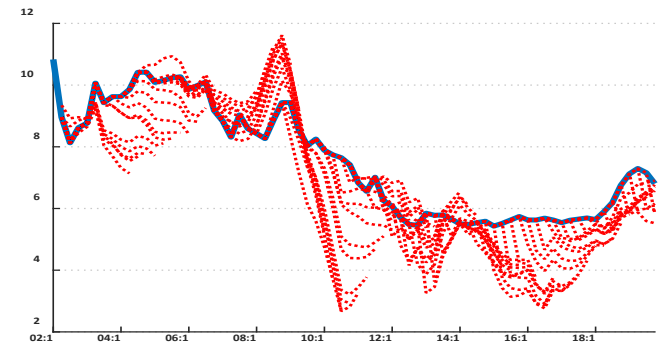

Source: Authors' computation

In sum, errors in forecasting the policy rate seem to be causing errors in the lending rate forecast. While credit premium is predicted better by the model compared to a random walk, the lending rate forecasts are worse driven by policy rate forecasts. The poor lending rate forecasts in turn impair the forecast of the credit gap forecast.

\section{Historical InTERPRETATION OF THE DATA USING THE QPM}

We saw in the previous section that the model's in-sample forecasts are reasonably informative, and that the main errors have to do with the apparently-evolving policy rule. This section asks in effect how well the model predicts the past. That is, how we show that the model is useful in interpreting recent economic developments in the Philippines, based on a historical shock decomposition analysis using the Kalman filter. The ability of a model to help understand the 
imbalances and shocks that have shaped recent economic events is an important test of its usefulness for policymakers.

\section{Kalman Filtration}

We now use the calibrated QPM to interpret the Philippine historical data. That is, we use the Kalman filter to find the trends and the values of the structural shocks that best fit the historical data. Data filtration over history serves two purposes: (i) it produces estimates of unobserved variables, including trends and shocks; and (ii) the estimated structural shocks, in turn, provide an interpretation of historical developments. The confrontation of the latter with expert judgment serves to validate the model.

Three groups of observed variables inform the filtration. The first is related to the business cycle block of the model, following Guo et al. (2019). This includes the headline CPI, including the core and food-and-energy components, real GDP, the GDP deflator, shares of exports and imports in GDP, the nominal exchange rate, and the policy interest rate. It also incorporates foreign variables, namely global CPI, GDP, and oil and food commodity prices, and U.S. interest rates. The second group of observed data relate to the credit cycle and macroprudential policy blocks. This consists of outstanding bank credit to firms, the lending rate, and the VIX. And the third consists of bank-related data on total assets of banks, ROAs, and total banks' capital. ${ }^{44}$

We use a Kalman filter, which assumes linearity of the model in computing the mean and variance of all model variables based on observed data. We exploit this filtration technique, despite non-linearity in important blocks of the model, for several reasons. First, most software packages used to solve similar models exploit the linear filters and use a first-order approximation of the model solved around its steady state or a balance growth path. ${ }^{45}$ Second, although non-linear filtration procedures are available, they are computationally demanding, involving a non-trivial computation of the variance of state variables. Third, nonlinear filters usually require stationarity of all model variables, which in our model would require rendering all model variables stationary along the balance growth path or de-trending all observed variables.

Our final justification for using the linear filter is that we can use expert tunes to address critical nonlinearities, notably in dividend payoffs (equation 18) and the nonzero spread (equation 17). ${ }^{46}$ Mechanically, applying the expert tunes entails restricting the dividends and bank spread values to be non-negative. This requires running the Kalman filtration twice. In the first run, no expert restrictions on dividends and spread are imposed. In the second run,

\footnotetext{
${ }^{44}$ We assume measurement errors do not exist in the observed data. The variables are not de-trended but are seasonally adjusted where applicable. The VIX is de-meaned. Observations of the $1 \mathrm{Y}$ benchmark rate are not available. Observations of $1 Y$ rate would help to distinguish the term and the credit premium and their dynamics. Without actual data on the rate, the term premium is assumed to be constant, and the spread between the credit and the policy rate has to be captured by the credit premium and the lending spread induced by regulatory requirement.

${ }^{45}$ We solve the model using IRIS toolbox, documented in https://iris.igpmn.org/.

${ }^{46}$ See Simon (2009) for detail regarding the Kalman filtration under constraints and non-linear modifications.
} 
dividends and the spread are set to zero in periods where they are found to be negative in the first run. ${ }^{47}$

The model-based filtration suggests that credit gap was relatively moderate in terms of peaks. This means that credit did not significantly deviate from its equilibrium (trend) value and thus implies that it did not threaten significantly financial stability. Figure VI.1 presents credit flow and the trend as calculated by the Kalman filter. Figure VI.2 presents the gap, and shows that the positive credit gap closed rapidly in 2019. A positive credit gap started to open in 2016, peaking at about 0.5 percent in 2018 (Figure VI.2, smoothed credit gap, black line).

Figure VI.1: Credit flow to GDP (percent)

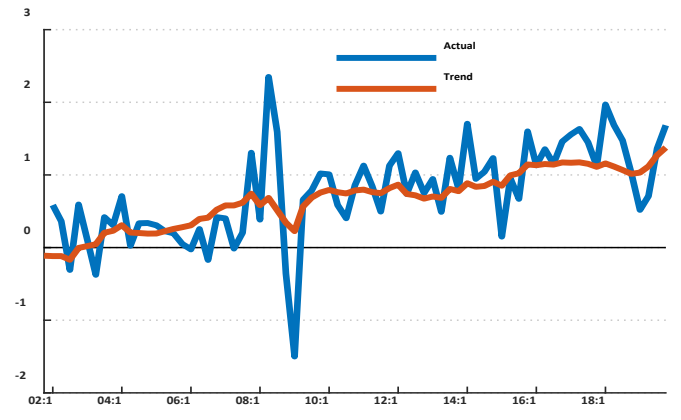

Source: Authors' computation
Figure VI.2: Credit gap flow to GDP (percent)

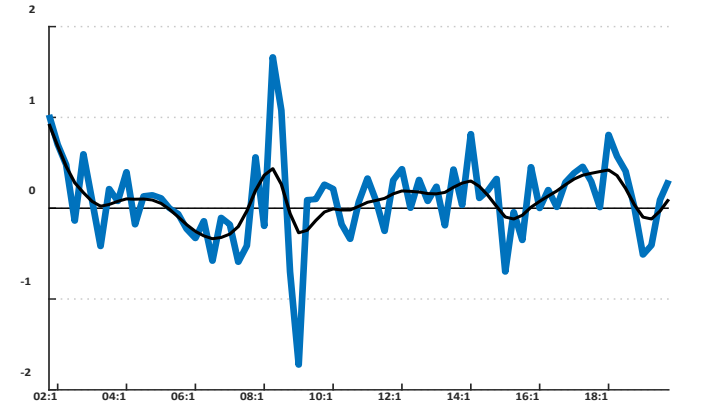

Note: The black line denotes the smoothed credit gap applying HP filter with lambda $=5$ to remove high frequencies from the estimate. This additional smoothing helps visualize the position of the credit gap.

Source: Authors' computation

\section{Historical shock decomposition analysis}

Credit gap decomposition. Figure VI.3 provides a decomposition of the credit gap based on equation (3), which considers the underlying determinants of demand for credit. The real lending rate has been an important determinant of demand for credit, i.e., the credit gap (orange bars). The contribution of credit shocks (purple bars), capturing financial shocks and other credit determinants not explicitly modeled, is pronounced, and appear to offset the effect of the real lending rate gap (for e.g., in 2008, 2015, and 2018). The output gap capturing the business cycle position (red bars) appears to have somewhat a lower impact on the credit gap in comparison with the real lending rate or the credit demand shock.

Similar conclusions can be drawn from the decomposition of the credit gap with a focus on the contributions of structural shocks (Figure VI.4), over the 2002-2019 period. Figure VI.4 shows how the credit gap decomposes into the effects of the particular shocks featured in the model. Domestic and foreign business cycle shocks, along with monetary policy shocks have played an important role. It is evident that domestic economic developments (blue bars) have been the main factor in closing the positive credit gap in 2018-2019, and that monetary policy, including

\footnotetext{
${ }^{47}$ The expert tunes are applied by introducing an auxiliary observed variable with observations in selected periods where expert tunes are applied, otherwise they are empty.
} 
exchange rate developments (red bars), have worked to smooth the credit cycle in partly offsetting the effects of domestic demand and supply shocks (blue bars) since 2016.

Figure VI.3: Credit gap decomposition (percentage point)

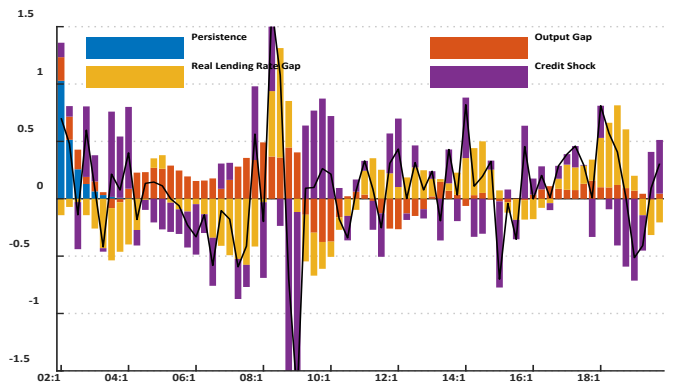

Note: Decomposition is based on equation (3). Bars in each period sum up to the black line, which is the credit gap. The lagged term (persistence) is replaced by lagged output and lending rate gaps.

Thus, the effect of the lagged credit is only seen at the beginning of sample.

Source: Authors' computation
Figure VI.4: Credit gap decomposition to underlying structural shocks (percentage point)

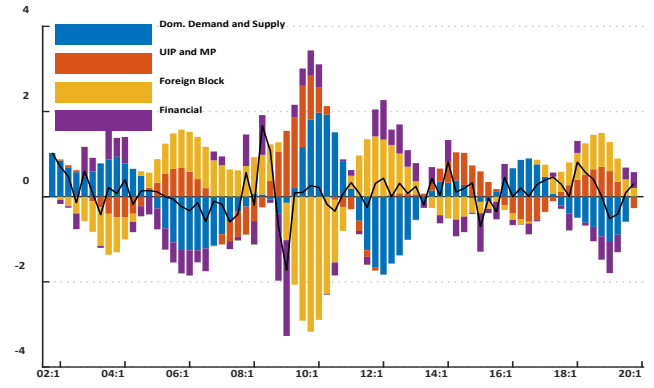

Note: Decomposition to structural shocks. Bars in each period sum up to the black line which is the credit gap.

Source: Authors' computation

The lending rate is driven by the policy rate, adjusted for premia. Figure VI.5 shows the decomposition of the lending rate in terms of the contribution of the $1 \mathrm{Y}$ rate, the two premia (term and credit risk), and the spread. The contribution of the term premium is constant, following a model assumption of no variation in the term premium. ${ }^{48}$ Consequently, dynamics of the credit rate is driven by the $1 \mathrm{Y}$ benchmark rate and the credit premium. The $1 \mathrm{Y}$ benchmark rate is not observed and is estimated by the filter as a risk-free rate using the current and expected policy rate, i.e. the term structure of the forward policy interest rates. Contributions of the spread (applied by U/KBs to meet the leverage ratio) are small and are featured mainly in the first half of the filtration period.

The credit premium is estimated to be close to its neutral level in 2019 (Figure VI.6). It reflects the riskiness of debt contracts and is determined by the expected future business cycle developments (red bars). The credit premium also reflects world financial conditions, approximated by the VIX index. In a small open economy of the Philippines, world capital flows largely affect domestic financial conditions, as in other EMDEs. In this regard, the Philippines has experienced large capital outflows in the wake of the global financial crisis, which contributed to a rise in the credit premium during 2008-2013 (orange bars). Last, the structural shocks to the credit premium captures factors not explicit in the model, e.g., loan promotions and public support to market segments, among others (purple bars). ${ }^{49}$

\footnotetext{
${ }^{48}$ The assumption is a simplification adopted to allow the model to distinguish between the term and credit premia.

${ }^{49}$ Note that the credit premium is assumed to be persistent in the model (equation 8 ) and the lag term capturing this persistency is substituted out in the decomposition (Figure VI.6), i.e. it is replaced by lagged factors. Therefore, the persistent contribution of the shock to the credit premium in the decomposition does not necessarily mean that the shock is autocorrelated. Rather, it signifies persistent, and lasting in nature, contribution.
} 
Figure VI.5: Lending rate (in percent per annum); Contributions (percentage point)

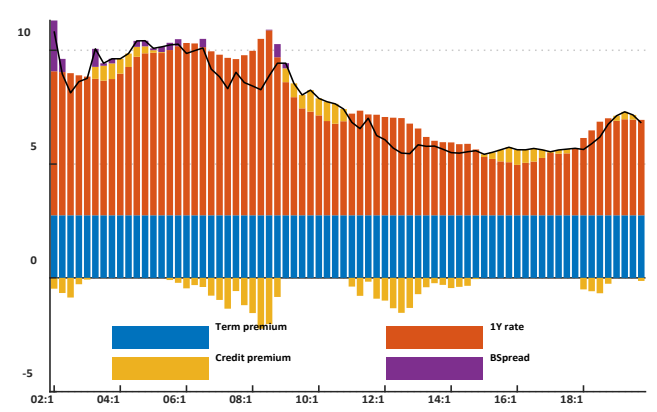

Note: Bars in each period of time sum up to the black line which is the credit rate.

Source: Authors' computation
Figure VI.6: Credit premium (in percent per annum); Contributions (percentage point)

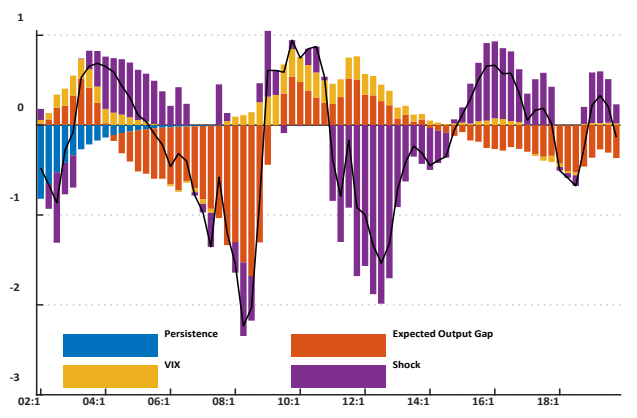

Note: Bars in each period of time sum up to the black line which is the credit premium. The lagged term is replaced by expected output gaps and lagged VIXs. Thus, the effect of persistence is only at the beginning of sample, capturing the starting point.

Source: Authors' computation

The real lending rate has fluctuated around 3 percent since 2008. Figure VI.7 plots the real lending rate and its real equilibrium level. The latter equals the natural real interest rate, adjusted for the constant term premium. Based on an earlier assumption reflected in equation (7), along with a strong correlation between the policy and the lending rate, it implies a co-movement of these rates (in gap terms) (Figure VI.8).

Figure VI.7: Real lending rate (percent, per annum)

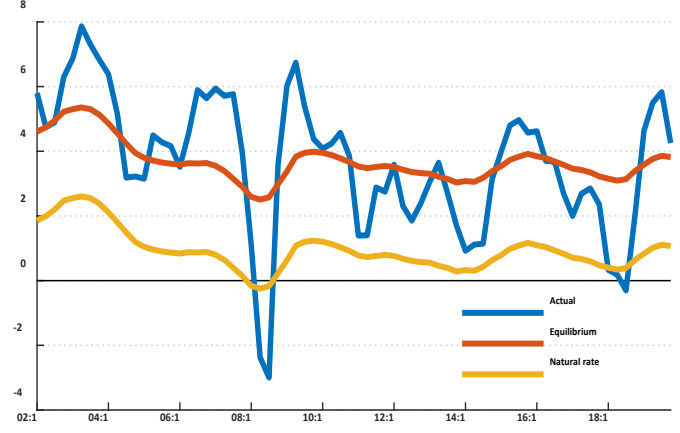

Source: Authors' computation
Figure VI.8: Real lending rate and policy rate in gap terms (percent, per annum)

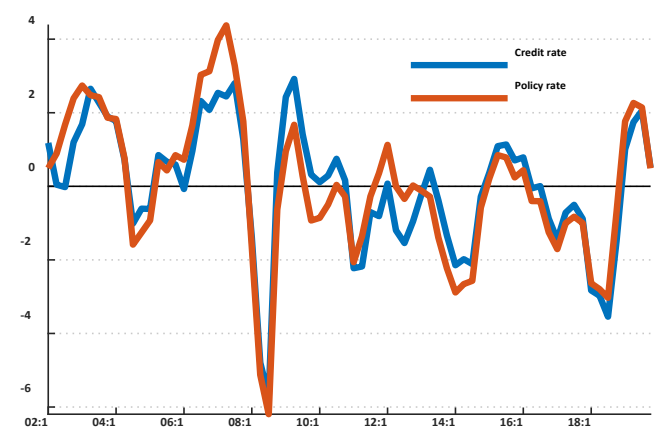

Source: Authors' computation

Actual data on the size of bank balance sheet, capital, and ROAs are available from 2008Q2 onward. Prior to 2008, these variables are assumed to be unobserved in the model and therefore estimated using the model and Kalman filtration.

The leverage ratio has fluctuated around 12 percent since 2011, with significant spike in 2012-2013. Under no requirement explicitly set for the leverage ratio, an implicit target at 11 percent is assumed in calibrating the model's steady state, which seems to be below the historical average observed in the data (Figure VI.9). The latter choice of the target is ad-hoc although it reflects a practice that banks, including in the Philippines, keep buffers above the 
regulatory requirements, unless they experience stress. Consistent with that, the banks' (lending) spread (the part triggered by regulatory requirements) is estimated to be close to zero on average (Figure VI.11), and dividend payments are positive (Figure V.10). While a useful insight, these estimates cannot be confronted with the actual data as both spreads and dividend payout ratios are unobserved.

Figure VI.9: Leverage ratio (total bank capital Figure VI.10: Dividends to total assets (percent) to total assets) (percent)
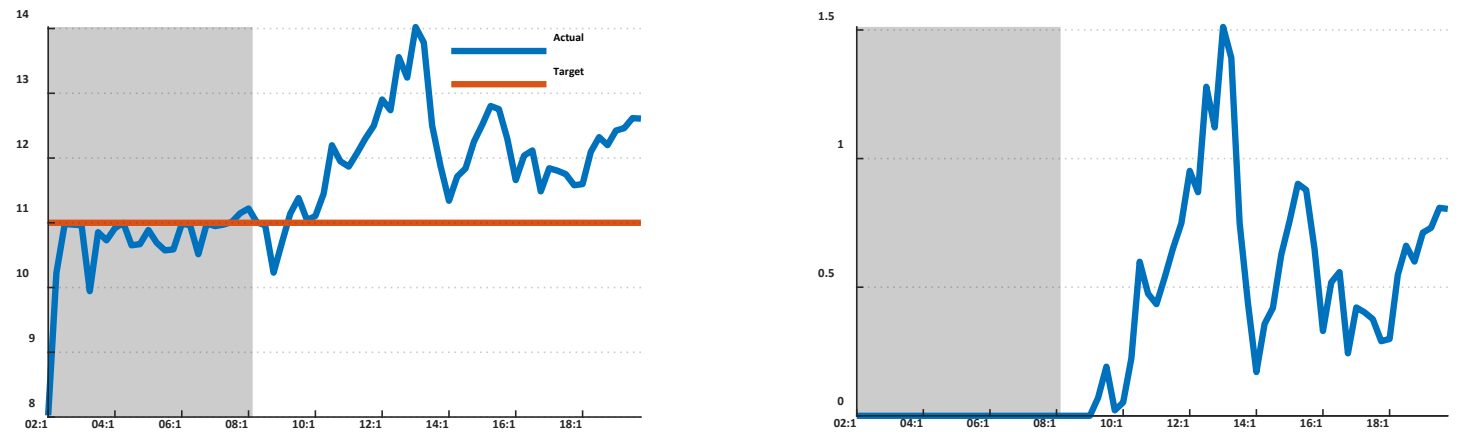

Note: The grey area covers the periods for which the actual data on banking sector are not available.

Note: The grey area covers the periods for which the actual data on banking sector are not available.

Source: Authors' computation

Source: Authors' computation

ROA is relatively stable at around 1.5 percent (Figure VI.12). A stable ROA reflects accumulation of capital in line with the growth of banks' assets. The predicted value in Figure VI.12 shows that the estimate based on filtration hovers around the average level of the ROA in the data. ${ }^{50}$

Figure VI.11: Spread induced by the regulatory requirements (percent)

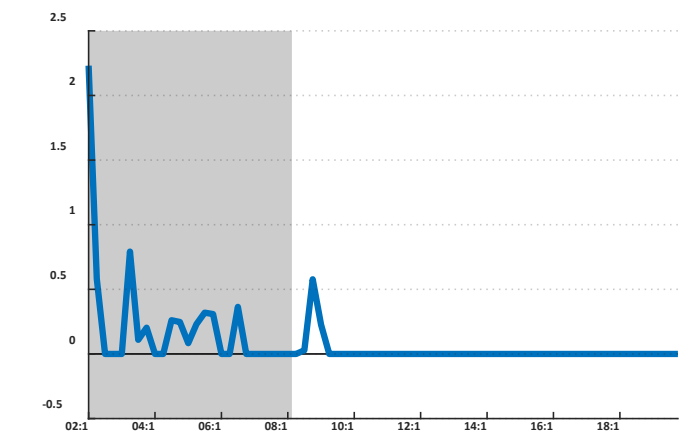

Figure VI.12: Return on assets (ROA) (percent)

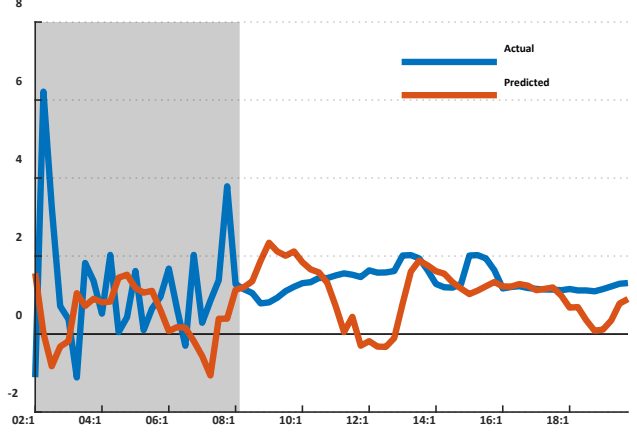

Note: The grey area covers the periods for which the actual data on banking sector are not available.

Note: The grey area covers the periods for which the actual data on banking sector are not available.

Source: Authors' computation

Source: BSP and authors' computation

\footnotetext{
${ }^{50}$ The predicted value is the ROA adjusted by the shock to profitability. As the shock is expected to be zero, this measure can be viewed as a one step-ahead forecast.
} 
Feedback from financial sector shocks to business cycle does not amount to much. In gauging the financial sector feedback (namely the credit feedback) to output gap which captures the business cycle, it does not seem to have affected the gap significantly in the past (purple bars) (Figure VI.13). Focusing next on the decomposition of the output gap to structural shocks (Figure VI.14), it was similarly found that shocks in the financial sector do not play an important role shaping the output gap. However, this does not mean that the passthrough is weak, as it may just be an artifact of historical observations without a crisis or significant financial stress in the Philippines during the period chosen for analysis. It is not unusual to guess that financial crisis or stress might negatively affect economic developments.

Figure VI.13: Output gap decomposition to factors based on model equation (13) (percent); and Contributions (percentage point)

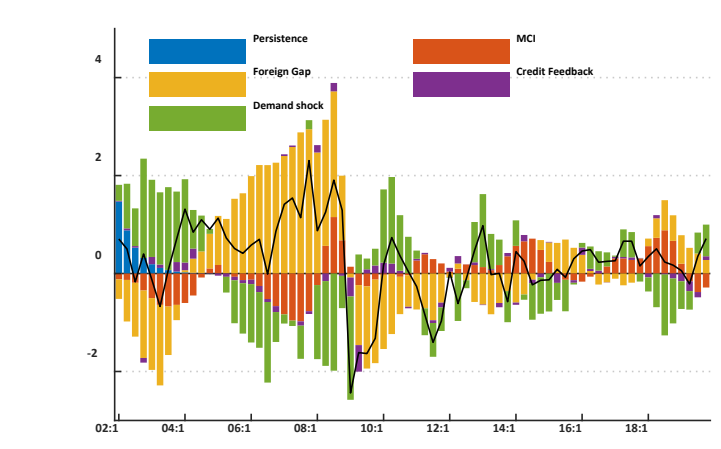

'Source: Authors' computation
Figure VI.14: Output gap decomposition to structural shocks (percent); and Contributions (percentage point)

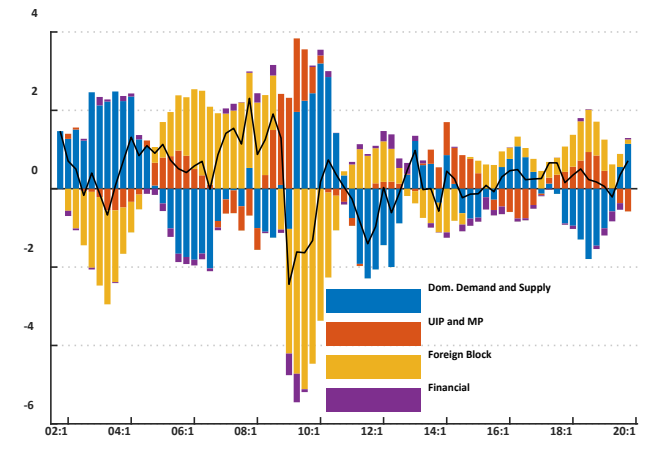

Source: Authors' computation

\section{CONCLUSION}

In this paper, we present a practical Quarterly Projection Model that incorporates endogenous interactions between the financial sector and the rest of the economy, illustrating its usefulness with application to the Philippines. The goal is to facilitate the joint forecasting and policy analysis of both the traditional concerns of IT-oriented central banks - notably the policy interest rate, inflation, the output gap, and the exchange rate - and key macroeconomic aspects of the financial sector, notably credit growth and macroprudential measures.

We extend earlier work (Guo et al. (2019)) that analyzed the monetary policy stance and inflation pressures during the 2018 exchange rate stress period with a focus on the impact of exchange rate and trade dynamics. Here we focus on credit cycle behavior and the role of macroprudential policy to moderate credit growth, including interactions with the policy rate.

We parameterize the model based on a mix of calibration and Bayesian estimation methods. We study model properties and use extensive evaluation exercises to highlight strengths and weaknesses. We find that the model's impulse response functions are satisfactory. In particular, they improve model dynamics and usefully illustrate the role of macroprudential measures in addressing financial stability. Historical shock decompositions quantify the contributions of 
various exogenous shocks to the dynamics of macroeconomic and financial variables of interest, including the output gap, credit gap and credit premium.

The main purpose of the paper is to present and illustrate the usefulness of the tool for forecasting and policy analysis. A critical feature of the model for its intended purpose is its relative simplicity. Many design choices promote simplicity, tractability, and usefulness for regular forecasting and policy analysis. These choices include its mainly-linear structure and the careful addition of just a small number of additional financial variables and equations: notably a credit block and a macro-prudential block.

Despite the efficiency of the additions, a rich picture emerges of the interactions between these blocks and the broader macroeconomy. The structure of the endogenous equations and underlying variables related to credit and regulatory components have provided the model with better dynamics. We can disentangle the role of risk appetite, credit supply shocks, and other macroeconomic factors in driving credit growth. And we can analyze jointly the effects of both the policy interest rate and macroprudential measures - specifically targets on financial sector leverage ratios - on credit and other key macroeconomic variables. Substantively, an important finding is that the business cycle seems to lead the financial cycle in the Philippines. In the historical sample, there seems to be little feedback from financial shocks to the rest of the economy. One interpretation is that such feedback occurs mainly with large shocks or crises such as were not observed here. In any case, this paper's ability to track and explain credit growth and link it to policies should be useful to policymakers concerned about macroeconomic implications of financial sector developments.

The goal in this line of work is to provide policymakers with structured tools for forecasting and policymaking. We show that the model presented here can help understand historical macroeconomic and financial sector data, interpret the current disequilibria in these sectors, and help make forecasts that are contingent on monetary and macroprudential policy. The flexible model structure can with simple modifications and extensions readily incorporate sector-specific financial risks, depending on the specific concerns of policymakers in particular cases. Such risks could include growing real estate credit or unhedged corporate foreign-currency borrowing, house prices, long-term household debt imbalances, or FX exposure to dollarized liabilities. ${ }^{51}$ The model could then help evaluate the implications of specific macroprudential measures, such as borrower-based tools (for e.g., LTV caps) to affect household deleveraging and targeted exposure caps in vulnerable industries to contain FX exposure. ${ }^{52}$

\footnotetext{
${ }^{51}$ See Kim (2019) and Kim et al. (2020) for the case of non-financial firm leveraging and FX exposure in the Philippines, and to a larger number of emerging market economies. Beyond the targeted macroprudential measures prescribed, policies that promote domestic financial market development in the long run, should be encouraged as they would help reduce exposure to exchange rate fluctuations. It is worth mentioning, Asian EM have exhibited large and often unhedged FX liabilities of corporates and banks, which could make the exchange rate a shock amplifier, considering the balance sheet channel.

${ }^{52}$ Macroprudential analytical tools developed at the IMF, backed by cost-benefit analysis and the (iMaPP) database would be helpful in this regard (see Alam et al. (2019); Chen et al (2020)).
} 


\section{REFERENCES}

Acosta-Ormaechea, S. and L. Martinez, 2021 "A Guide and Tool for Projecting Public Debt and Fiscal Adjustment Paths with Local- and Foreign-Currency Debt", Institute for Capacity Development, IMF Technical Notes and Manuals 2021/005.

Adler. G., C. Casas, L. Cubeddu, G. Gopinath, N. Li, S. Meleshchuk, C. Osorio Buitron, D. Puy, and Y. Timmer, 2020, "Dominant Currencies and External Adjustment," IMF Staff Discussion Note, SDN 20/05, (Washington, DC: International Monetary Fund).

Adrian, T., and N. Liang. 2018. "Monetary Policy, Financial Conditions, and Financial Stability." International Journal of Central Banking 14(1): 73-131.

Adrian, T., C. Erceg, J. Linde, P. Zabczyk, and J. Zhou, 2020a, "Quantitative Model of the Integrated Policy Framework.” IMF Working Paper 20/122 (July), (Washington, DC: International Monetary Fund).

Adrian, T., 2020b, ““'Low for Long” and Risk-Taking,” IMF-MCM Departmental Paper Note 20/15, (Washington, DC: International Monetary Fund),

Adrian, T., F. Duarte, N. Liang, and P. Zabczyk, 2020c. "NKV: A New Keynesian Model with Vulnerability." AEA Papers and Proceedings 110: 470-76.

Aikman, D., A.G. Haldane, and B.D. Nelson, 2015, "Curbing the Credit Cycle," Economic Journal, 125(585), 1072-109.

Alam, Z., A. Alter, J. Eiseman, G. Gelos, H. Kang, M. Narita, E. Nier, and N. Wang, 2019, "Digging Deeper-Evidence on the Effects of Macroprudential Policies from a New Database," IMF Working Paper 19/66 (March), (Washington, DC: International Monetary Fund).

Andrle, M., 2010, “A Note on Identification Patterns in DSGE Models," ECB Working Paper no. 1235 (European Central Bank).

Basel Committee on Banking Supervision (BCBS), 2010. Guidance for National Authorities Operating the Countercyclical Capital Buffer. https://www.bis.org/publ/bcbs187.pdf

Baksa, D., A. Bulír, and D. Heng, 2020, “A Simple Macrofiscal Model for Policy Analysis: An Application to Cambodia," IMF Working Paper 20/202 (September), (Washington, DC: International Monetary Fund).

Baksa, D., A. Bulír, and R. Cardarelli, 2021, "A Simple Macrofiscal Model for Policy Analysis: An Application to Morocco," IMF Working Paper 21/190 (July), (Washington, DC: International Monetary Fund).

Buliř, A., D. Baksa, J.S. Corrales, A. González-Gomez, D. Heng, and D. Rodríguez-Guzman, "Using Macroeconomic Frameworks to Analyze the Impact of COVID-19: An Application to Colombia and Cambodia," Institute for Capacity Development, IMF Technical Notes and Manuals 2021/001. 
Bernanke, B.S., Gertler, M. and Gilchrist, S. (1999), "The Financial Accelerator in a Quantitative Business Cycle Framework", in: John B. Taylor and Michael Woodford, eds., Handbook of Macroeconomics, Volume 1C. Amsterdam: Elsevier

Brandao-Marques, L., G. Gelos, M. Narita, and E. Nier, 2020, "Leaning Against the Wind: A Cost-Benefit Analysis for an Integrated Policy Framework.” IMF Working Paper 20/123 (July), (Washington, DC: International Monetary Fund).

Byggs M. and T. Mayer, 2013, "Bring Credit Back into the Monetary Policy Framework," PEFM Policy Brief. https://www.sant.ox.ac.uk/sites/default/files/pefmcreditpolicybrief.pdf

Chen, J., D. Finocchiaro, J. Lindé, and C.R. Nunes, 2020, “The Costs of Macroprudential Deleveraging in a Liquidity Trap,” IMF Working Paper 20/89 (June), (Washington, DC: International Monetary Fund).

Guo, S., P. Karam, and J. Vlcek, 2019, "Decomposing the Inflation Dynamics in the Philippines," IMF Working Paper 19/153 (July), (Washington, DC: International Monetary Fund).

International Monetary Fund, 2015, "Monetary Policy and Financial Stability." IMF Policy Paper. (Washington, DC: International Monetary Fund). ,2020, "Towards an Integrated Policy Framework," (month?), (Washington, DC: International Monetary Fund).

Juillard, M., C. Freedman, D. Korshunov, D. Laxton, O. Kamenik, I. Carabenciov, I. Ermolaev, and J. Laxton, 2008, "A Small Quarterly Multi-Country Projection Model with Financial-Real Linkages and Oil Prices," IMF Working Paper 08/280 (December).

Kalemli-Ozcan, S., 2019, “U.S. Monetary Policy and International Risk Spillovers," Jackson Hole Symposium Proceedings.

Kim, M., 2019, "Financial Development, Exchange Rate Fluctuations and Debt Dollarization: A Firm-Level Evidence,” IMF Working Paper 19/168 (August), (Washington, DC: International Monetary Fund).

Nier, E., T. T. Olafsson, and Y. G. Rollinson, 2020, "Exchange Rates and Domestic CreditCan Macroprudential Policy Reduce the Link?" IMF Working Paper 20/187 (September), (Washington, DC: International Monetary Fund).

Simon, D., 2009, "Kalman Filtering with State Constraints: A Survey of Linear and Nonlinear Algorithms," IET Control Theory and Applications. https://academic.csuohio.edu/simond/pubs/IETKalman.pdf

Svensson, L.EO, 2017, "Cost-Benefit Analysis of Leaning Against the Wind," Journal of Monetary Economics 90: 193-213.

Van den Hof P.M.J., J.F.M. Van Doren, and S.G. Douma, 2009, "Identification of Parameters in Large Scale Physical Model Structures, for the Purpose of Model-Based Operations," In: Hof P., Scherer C., Heuberger P. (eds) Model-Based Control. Springer, Boston, MA. 
Vlcek, J., M. Pranovich, P. Hitayezu, B. Mwenese, and C. Nyalihama, 2020, "Quarterly Projection Model for the National Bank of Rwanda," IMF Working Paper 20/295 (December), (Washington, DC: International Monetary Fund). 


\section{APPENDIX A. Model Variables}

\begin{tabular}{|c|c|}
\hline Variable & Description \\
\hline$y$ & Real GDP, $100 * \ln$ \\
\hline$\hat{y}$ & Output gap, percent \\
\hline $\bar{y}$ & Potential GDP, $100 * \ln$ \\
\hline$\Delta y$ & Real GDP growth, annualized q-o-q, percent \\
\hline$\Delta^{4} y$ & Real GDP growth, y-o-y, percent \\
\hline$\Delta \bar{y}$ & Real GDP Trend growth, annualized q-o-q, percent \\
\hline$\Delta^{4} \bar{y}$ & Real GDP Trend growth, y-o-y, percent \\
\hline$E_{t} \hat{y}_{t+1}$ & Output gap, percent \\
\hline cpi & Headline CPI, $100 * \ln$ \\
\hline$\pi$ & Headline CPI inflation, annualized q-o-q, percent \\
\hline$\pi 4$ & Headline CPI inflation, y-o-y, percent \\
\hline$c p i^{C}$ & Core CPI, $100 * \ln$ \\
\hline$\pi^{C}$ & Core CPI inflation, annualized q-o-q, percent \\
\hline$\pi 4^{C}$ & Core CPI inflation, y-o-y, percent \\
\hline$r m c^{C}$ & Real marginal costs - core inflation, percent \\
\hline$c p i^{F}$ & Food CPI, $100 * \ln$ \\
\hline$\pi^{F}$ & Food CPI inflation, annualized q-o-q, percent \\
\hline$\pi 4^{F}$ & Food CPI inflation, y-o-y, percent \\
\hline$r m c^{F}$ & Real marginal costs - food inflation, percent \\
\hline$c p i^{E}$ & Energy CPI, $100 * \ln$ \\
\hline$\pi^{E}$ & Energy CPI inflation, annualized q-o-q, percent \\
\hline$\pi 4^{E}$ & Energy CPI inflation, y-o-y, percent \\
\hline$r m c^{E}$ & Real marginal costs - energy inflation, percent \\
\hline$s$ & Nominal exchange rate FRW to USD, $100 * \ln$ \\
\hline$\Delta s$ & Nominal ER depreciation of FRW to USD, annualized q-o-q, percent \\
\hline$\Delta^{4} S$ & Nominal ER depreciation of FRW to USD, y-o-y, percent \\
\hline prem & Country risk premium, percent \\
\hline$i^{M P}$ & Nominal policy interest rate, percent p.a. \\
\hline$r$ & Real interest rate, percent \\
\hline $\bar{r}$ & Equilibrium real interest rate, percent \\
\hline$\hat{r}$ & Real interest rate gap, percent \\
\hline$i^{\text {Neutral }}$ & Nominal neutral interest rate, percent p.a. \\
\hline$z$ & Real exchange rate, $100 * \ln$ \\
\hline $\bar{z}$ & Equilibrium real exchange rate, $100 * \ln$ \\
\hline$\hat{z}$ & Real effective exchange rate gap, percent \\
\hline$\Delta \mathrm{z}$ & Real ER depreciation, annualized q-o-q, percent \\
\hline$\Delta \bar{z}$ & Equilibrium real exchange rate depreciation, annualized q-o-q, percent \\
\hline$\Delta^{4} \bar{Z}$ & Equilibrium real exchange rate depreciation, y-o-y, percent \\
\hline$E_{t} \Delta \bar{z}_{t+1}$ & Expected at time $t$ equilibrium real exchange rate depreciation at $t+1$, annualized q-o-q, percent \\
\hline rmci & Real monetary condition index, percent \\
\hline$\pi 4^{\mathrm{Tar}}$ & Inflation target for headline inflation, $\mathrm{y}-\mathrm{o}-\mathrm{y}$, percent \\
\hline$r p^{C}$ & Relative price of core to headline, $100 * \ln$ \\
\hline$\frac{r}{r p} C$ & Equilibrium relative price of core to headline, $100 * \ln$ \\
\hline$\Delta \overline{r p} C$ & Equilibrium relative price growth - core to headline, annualized q-o-q, percent \\
\hline$\widehat{r p}^{C}$ & Relative price gap - core to headline, percent \\
\hline$r p^{F}$ & Relative price of food to headline, $100 * \ln$ \\
\hline$\frac{p}{r p} F$ & Equilibrium relative price of food to headline, $100 * \ln$ \\
\hline$\Delta \overline{r p}{ }^{F}$ & Equilibrium relative price growth - food to headline, annualized q-o-q, percent \\
\hline$\widehat{r p}^{F}$ & Relative price gap - food to headline, percent \\
\hline$r p^{E}$ & Relative price of energy to headline, $100 * \ln$ \\
\hline$\frac{1}{r p}{ }^{E}$ & Equilibrium relative price of energy to headline, $100 * \ln$ \\
\hline
\end{tabular}




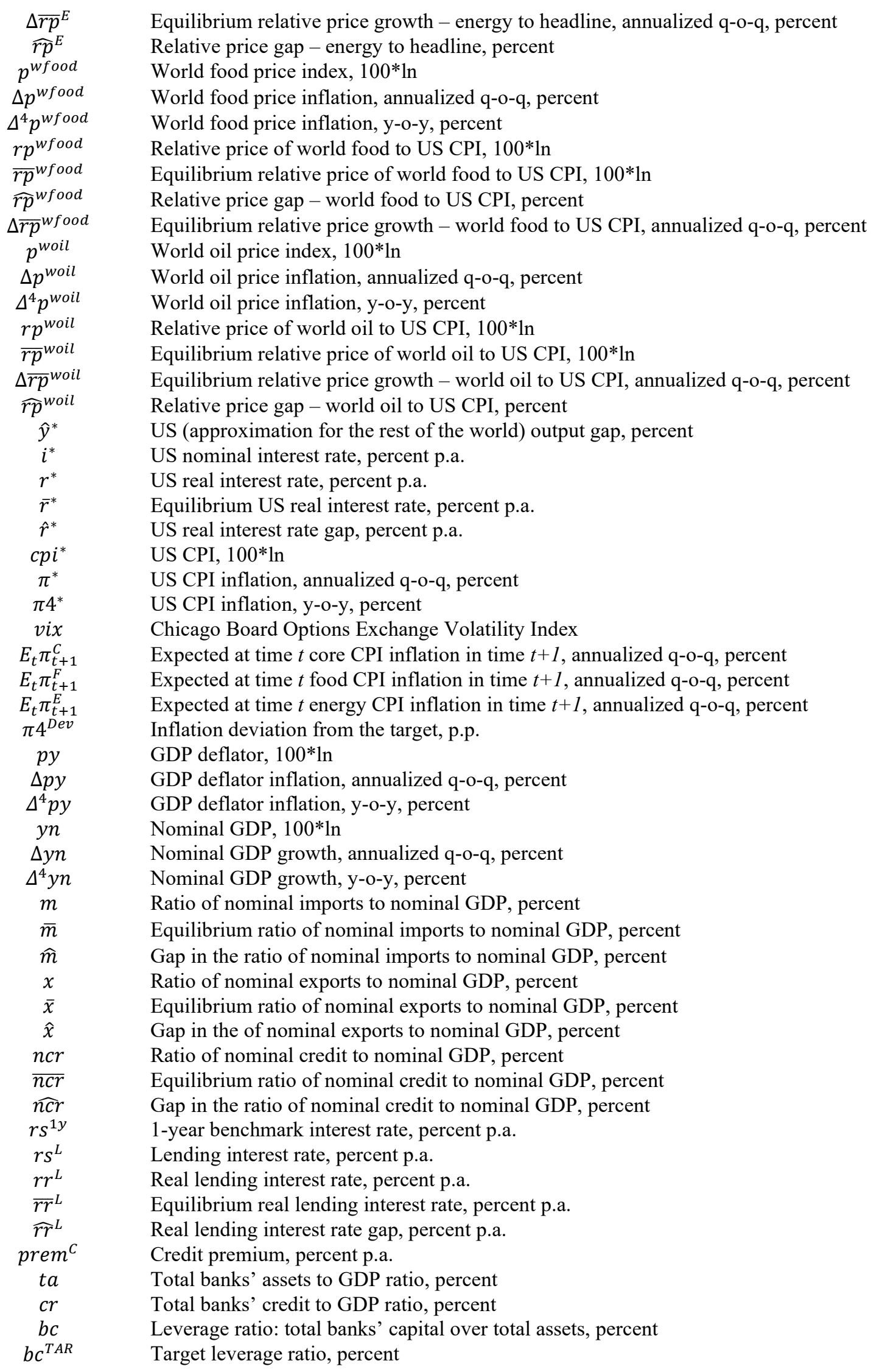




\begin{tabular}{|c|c|}
\hline$T A$ & Level of total banks' assets, units of local currency \\
\hline roa & Banks' returns on assets ratio, percent \\
\hline div & Banks' dividends: ratio of total dividends to assets, percent \\
\hline$s p$ & Spread (margin) banks include in lending rate to accelerate capital accumulation, percent \\
\hline$\varepsilon^{\hat{y}}$ & Shock to output gap, percent \\
\hline$\varepsilon^{\Delta \bar{y}}$ & Shock to equilibrium output, percent \\
\hline$\varepsilon^{\pi^{C}}$ & Shock to core subcomponent of inflation, percent \\
\hline$\varepsilon^{\pi^{F}}$ & Shock to food subcomponent of inflation, percent \\
\hline$\varepsilon^{\pi^{E}}$ & Shock to energy subcomponent of inflation, percent \\
\hline$\varepsilon^{\pi^{T A R}}$ & Shock to inflation target, percent \\
\hline$\varepsilon^{s}$ & Shock to the nominal effective exchange rate, percent \\
\hline$\varepsilon^{\Delta S^{T A R}}$ & Shock to the nominal effective exchange rate target, percent \\
\hline$\varepsilon_{t}^{i^{M P}}$ & Shock to the domestic policy interest rate (monetary policy shock), percent \\
\hline$\varepsilon^{\hat{y}^{*}}$ & Shock to US output gap, percent \\
\hline$\varepsilon^{i^{*}}$ & Shock to the US interest rate, percent \\
\hline$\varepsilon^{\pi^{*}}$ & Shock to US inflation, percent \\
\hline$\varepsilon^{\bar{r}^{*}}$ & Shock to the US equilibrium real interest rate, percent \\
\hline$\varepsilon^{\Delta \bar{z}}$ & Shock to the long-term rate of change in real effective exchange rate, percent \\
\hline$\varepsilon^{\text {prem }}$ & Shock to country risk premium, percent \\
\hline$\varepsilon^{\widehat{r p}^{o i l}}$ & Shock to the cyclical component (gap) in relative oil prices, percent \\
\hline$\varepsilon^{\Delta \overline{r p}^{o i l}}$ & Shock to the trend in relative oil prices, percent \\
\hline$\varepsilon^{\widehat{r p}^{\text {food }}}$ & Shock to the cyclical component (gap) in world food prices relative to US CPI, percent \\
\hline$\varepsilon^{\Delta \overline{r p}}$ food & Shock to the trend in world food prices relative to US CPI, percent \\
\hline$\varepsilon^{\Delta \overline{r p}^{C}}$ & Shock to the rate of growth of trend in domestic core CPI subcomponent relative to headline CPI, percent \\
\hline$\varepsilon^{\Delta \overline{r p}} \bar{T}^{E}$ & Shock to the rate of growth of trend in domestic energy CPI subcomponent relative to headline CPI, percent \\
\hline$\varepsilon^{\Delta p y}$ & $\mathrm{AR}(1)$ shock in the process for GDP deflator, percent \\
\hline$\varepsilon^{n c r}$ & Credit demand shock, percent \\
\hline$\varepsilon^{\Delta \overline{n c r}}$ & Shock to the equilibrium rate of growth in credit flow-to-GPD, percent \\
\hline$\varepsilon^{\overline{n c r}}$ & Permanent level shifting shock to the trend in credit flow-to-GPD, percent \\
\hline$\varepsilon^{r s^{1 y}}$ & Shock to the benchmark 1-year rate, percent \\
\hline$\varepsilon^{\text {prem }^{C}}$ & Shock to the credit premium, percent \\
\hline$\varepsilon^{t a}$ & Shock to the asset side of the banks' balance sheet \\
\hline$\varepsilon^{b c}$ & Shock to capital accumulation (leverage ratio), percent \\
\hline$\varepsilon^{b c^{T A R}}$ & Shock to the target level of the leverage ratio, percent \\
\hline$\varepsilon^{s p}$ & Shock to the margin, percent \\
\hline$\varepsilon^{\text {div }}$ & Shock to the dividend payoff, percent \\
\hline$\varepsilon^{r o a}$ & Shock to the return-on-assets ratio, percent \\
\hline$\varepsilon^{v i x}$ & Shock to VIX, percent \\
\hline$\varepsilon^{\bar{x}}$ & Shock to the equilibrium ratio of nominal exports to nominal GDP, percent \\
\hline$\varepsilon^{\hat{x}}$ & Shock to the gap in the ratio of nominal exports to nominal GDP, percent \\
\hline$\varepsilon^{\bar{m}}$ & Shock to the equilibrium ratio of nominal imports to nominal GDP, percent \\
\hline$\varepsilon^{\hat{m}}$ & Shock to the gap in the ratio of nominal imports to nominal GDP, percent \\
\hline$\epsilon^{c p i}$ & Measurement error in equation for headline CPI as a weighted average of CPI subcomponents, percent \\
\hline$e^{\Delta p y}$ & IID Shock in AR(1) process for the shock to GDP deflator, percent \\
\hline
\end{tabular}




\section{APPENDIX B. Model Equations}

Only dynamic equations and definitions for trends and gaps are reported here. Remaining are some definitions, including for growth rates. All variables are in natural logs of respective variables unless noted otherwise. $\Delta$ is for q-o-q annualized growth rates, and $\Delta^{4}$ is for $y-0-y$ growth rates. Shocks have zero mean and to not be autocorrelated.

\section{Real GDP}

$$
\begin{gathered}
y_{t}=\hat{y}_{t}+\bar{y}_{t} \\
\hat{y}_{t}=b_{1} \hat{y}_{t-1}-b_{2} m c i_{t}+b_{3} \hat{y}_{t}^{*}+b_{6} \varepsilon_{t-1}^{\widehat{n c r}}+\epsilon_{t}^{\hat{y}} \\
\Delta \bar{y}_{t}=\rho^{\Delta \bar{y}_{\Delta-1}} \bar{y}_{t-1}+\left(1-\rho^{\Delta \bar{y}}\right)\left(\Delta \bar{y}_{s s}+\alpha^{\Delta \bar{y}} \Delta \overline{n c r}_{t}\right)+\varepsilon_{t}^{\Delta \bar{y}}
\end{gathered}
$$

Real monetary conditions index

$$
m c i_{t}=b_{4}\left(b_{5} \widehat{r r}_{t}+\left(1-b_{5}\right) \widehat{r r}^{L}\right)+\left(1-b_{4}\right)\left(-\hat{z}_{t}\right)
$$

Inflation

$$
c p i_{t}=w^{C} c p i_{t}^{C}+w^{F} c p i_{t}^{F}+\left(1-w^{C}-w^{F}\right) c p i_{t}^{E}+\epsilon_{t}^{c p i}
$$

Inflation: Core inflation

$$
\begin{gathered}
\pi_{t}^{C}=a_{11} E_{t} \pi_{t+1}^{C}+\left(1-a_{11}\right) \pi_{t-1}^{C}+a_{21} r m c_{t}^{C}+\varepsilon_{t}^{\pi C} \\
r m c_{t}^{C}=a_{31} \hat{y}_{t}+\left(1-a_{31}\right)\left(\hat{z}_{t}-\widehat{r p}_{t}^{C}\right)
\end{gathered}
$$

Inflation: Food price inflation

$$
\begin{gathered}
\pi_{t}^{F}=a_{12} E_{t} \pi_{t+1}^{F}+\left(1-a_{12}\right) \pi_{t-1}^{F}+a_{22} r m c_{t}^{F}+\varepsilon_{t}^{\pi F} \\
r m c_{t}^{F}=a_{32} \hat{y}_{t}+\left(1-a_{32}\right)\left(\widehat{r p}_{t}^{w f o o d}+\hat{z}_{t}-\widehat{r p}_{t}^{F}\right)
\end{gathered}
$$

Inflation: Energy price inflation

$$
\begin{gathered}
\pi_{t}^{E}=a_{13} E_{t} \pi_{t+1}^{E}+\left(1-a_{13}\right) \pi_{t-1}^{E}+a_{23} r m c_{t}^{E}+\varepsilon_{t}^{\pi E} \\
r m c_{t}^{E}=a_{33} \hat{y}_{t}+\left(1-a_{33}\right)\left(\widehat{r p}_{t}^{\text {woil }}+\hat{z}_{t}-\widehat{r p}_{t}^{E}\right)
\end{gathered}
$$

Exchange rate

$$
\begin{gathered}
s_{t}=e_{1}\left(s_{t-1}+\frac{2}{4}\left(\Delta \bar{z}_{t}+\pi_{t}-\bar{\pi}^{*}\right)\right)+ \\
\ldots+\left(1-e_{1}\right) E_{t} s_{t+1}-\left(\frac{i_{t}}{4}-\frac{i_{t}^{*}}{4}-\frac{\text { prem }_{t}}{4}\right)+\varepsilon_{t}^{s}
\end{gathered}
$$

Monetary policy: Interest rate

\section{Real interest rate}

$$
\begin{gathered}
i_{t}^{M P}=g_{1} i_{t-1}^{M P}+\left(1-g_{1}\right)\left(i_{t}^{\text {Neutral }}+g_{2} E_{t} \pi 4_{t+3}^{D e v}+g_{3} \hat{y}_{t}\right)+\varepsilon_{t}^{i^{M P}} \\
\pi 4_{t+3}^{D e v}=E_{t} \pi 4_{t+3}-\pi 4_{t+3}^{T a r} \\
i_{t}^{\text {Neutral }}=\bar{r}_{t}+E_{t} \pi_{t+1}
\end{gathered}
$$

Real exchange rate

$$
\begin{gathered}
r_{t}=i_{t}-E_{t} \pi 4_{t+1} \\
r_{t}=\bar{r}_{t}+\hat{r}_{t} \\
\bar{r}_{t}=\rho^{\bar{r}} \bar{r}_{t-1}+\left(1-\rho^{\bar{r}}\right) \bar{r}_{s S}+\varepsilon_{t}^{\bar{r}}
\end{gathered}
$$




$$
\begin{gathered}
z_{t}=\bar{z}_{t}+\hat{z}_{t} \\
\Delta \bar{z}_{t}=\rho_{1}^{\Delta \bar{z}} \Delta \bar{z}_{t-1}+\left(1-\rho_{1}^{\Delta \bar{z}}\right)\left(\Delta \bar{z}_{s S}-\rho_{2}^{\Delta \bar{z}} \Delta \bar{y}_{t-1}\right)+\varepsilon_{t}^{\Delta \bar{z}}
\end{gathered}
$$

\section{Equilibrium version of UIP}

$$
\begin{aligned}
& \text { prem }_{t}=\rho^{\text {prem }} \text { prem }_{t}+\left(1-\rho^{\text {prem }}\right)\left(\bar{r}_{t}-\bar{r}_{t}^{*}-E_{t} \Delta \bar{z}_{t+1}\right)-\ldots \\
& \ldots-\alpha^{\text {prem }}(\hat{x}-\widehat{m})_{t}+\varepsilon_{t}^{\text {prem }}
\end{aligned}
$$

Relative prices

$$
\begin{aligned}
& r p_{t}^{C}=c p i_{t}^{C}-c p i_{t} \\
& r p_{t}^{C}=\overline{r p}_{t}^{C}+\widehat{r p}_{t}^{C} \\
& \Delta \overline{r p}_{t}^{C}=\rho^{\overline{r p}^{C}} \Delta \overline{r p}_{t-1}^{C}+\left(1-\rho^{\overline{r p}^{C}}\right) \Delta \overline{r p}_{s S}^{C}+\varepsilon_{t}^{\Delta \overline{r p}^{C}} \\
& r p_{t}^{F}=c p i_{t}^{F}-c p i_{t} \\
& r p_{t}^{F}=\overline{r p}_{t}^{F}+\widehat{r p}_{t}^{F} \\
& \Delta \overline{r p}_{t}^{F}=\rho^{\overline{r p}^{F}} \Delta \overline{r p}_{t-1}^{F}+\left(1-\rho^{\overline{r p}^{F}}\right) \Delta \overline{r p}_{s s}^{F}+\varepsilon_{t}^{\Delta \overline{r p}^{F}} \\
& r p_{t}^{E}=c p i_{t}^{E}-c p i_{t} \\
& r p_{t}^{E}=\overline{r p}_{t}^{E}+\widehat{r p}_{t}^{E} \\
& w^{C} \overline{r p}_{t}^{C}+w^{F} \overline{r p}_{t}^{F}+\left(1-w^{C}-w^{F}\right) \overline{r p}_{t}^{E}=0
\end{aligned}
$$

\section{Deflator and Nominal GDP}

$$
\begin{gathered}
\Delta p y_{t}=\rho^{\Delta p y} \Delta p y_{t-1}+\left(1-\rho^{\Delta p y}\right) \Delta c p i_{t-1}+\varepsilon_{t}^{\Delta p y} \\
\varepsilon_{t}^{\Delta p y}=\rho^{\varepsilon^{\Delta p y}} \varepsilon_{t-1}^{\Delta p y}+e_{t}^{\Delta p y} \\
\Delta y n_{t}=\Delta y_{t}+\Delta p y_{t}
\end{gathered}
$$

\section{Credit Cycle and Lending Rate}

$$
\begin{aligned}
& n c r_{t}=\overline{n c r}_{t}+\widehat{n c r}_{t} \\
& \widehat{n c r}_{t}=\rho^{\widehat{n c r}} \widehat{n c r}_{t-1}+\alpha_{1} \hat{y}_{t}-\alpha_{2} \widehat{r r}_{t}^{L}+\varepsilon_{t}^{\widehat{n c r}} \\
& \Delta \overline{n c r}_{t}=\rho^{\overline{n c r}} \Delta \overline{n c r}_{t-1}+\left(1-\rho^{\overline{n c r}}\right) \Delta \overline{n c r}^{s s}+\varepsilon_{t}^{\Delta \overline{n c r}} \\
& {\overline{n c r_{t}}}_{t}={\overline{n c r_{t-1}}}_{4}+\frac{\Delta \overline{n c r}_{t}}{4}+\varepsilon_{t}^{\overline{n c r}} \\
& r s_{t}^{1 y}=\rho^{r s^{1 y}} r s_{t-1}^{1 y}+\frac{\left(1-\rho^{r s^{1 y}}\right)\left[r s_{t}+r s_{t+1}+r s_{t+2}+r s_{t+3}\right]}{4}+p r e m^{T E R M}+\varepsilon_{t}^{r s^{1 y}} \\
& r s_{t}^{L}=r s_{t}^{1 Y}+\text { prem }_{t}^{C}+s p_{t} \\
& \text { prem }_{t}^{C}=\rho^{\text {prem }^{C}} \text { prem }_{t-1}^{C}-\alpha_{3} E_{t} \hat{y}_{t+1}+\alpha_{4} \text { vix }_{t}+\varepsilon_{t}^{\text {prem }^{C}} \\
& r r_{t}^{L}=r s_{t}^{L}-E_{t} \pi_{t+1} \\
& r r_{t}^{L}=\overline{r r}_{t}^{L}+\widehat{r r}_{t}^{L} \\
& \overline{r r}_{t}^{L}=\overline{r r}+\text { prem }^{T E R M}
\end{aligned}
$$

\section{Macroprudential Policy Block}

$$
\begin{gathered}
t a_{t}=c r_{t}+t a^{\text {wedge }}+\varepsilon_{t}^{t a} \\
b c_{t}=b c_{t-1} /\left(\frac{T A_{t}}{T A_{t-1}}\right)+r o a_{t}-d i v_{t}+\varepsilon_{t}^{b c} \\
b c_{t}^{T A R}=\rho^{b c^{T A R}} b c_{t-1}^{T A R}+\left(1-\rho^{b c^{T A R}}\right)\left(b c_{S S}^{T A R}+\phi \widehat{n C r}_{t}\right)+\varepsilon_{t}^{b c^{T A R}}
\end{gathered}
$$




$$
\begin{gathered}
s p_{t}=f_{o}\left(b c_{t}-b c_{t}^{T A R}\right)+\varepsilon_{t}^{s p} \\
d i v_{t}=f_{1}\left(b c_{t}-b c_{t}^{T A R}\right)+\varepsilon_{t}^{d i v} \\
r o a_{t}=\frac{r s_{t}^{L}-r s_{t}}{4}+c o s t^{a d j}+\varepsilon_{t}^{r o a}
\end{gathered}
$$

\section{Exports and Imports}

$$
\begin{gathered}
x_{t}=\hat{x}_{t}+\bar{x}_{t} \\
m_{t}=\hat{m}_{t}+\bar{m}_{t} \\
\bar{x}_{t}=\rho^{\bar{x}} \bar{x}_{t}+\left(1-\rho^{\bar{x}}\right) \bar{x}_{s s}+\varepsilon^{\bar{x}} \\
\bar{m}_{t}=\rho^{\bar{m}} \bar{m}_{t}+\left(1-\rho^{\bar{m}}\right) \bar{m}_{s s}+\varepsilon^{\bar{m}} \\
\hat{x}_{t}=\rho^{\hat{x}} \hat{x}_{t-1}+\alpha^{x z} \hat{z}_{t}+\alpha^{x y} \hat{y}_{t}^{*}+\varepsilon^{\hat{x}} \\
\widehat{m}_{t}=\rho^{\hat{m}} \widehat{m}_{t-1}-\alpha^{m z} \hat{z}_{t}+\alpha^{m y} \hat{y}_{t}+\varepsilon^{\hat{m}}
\end{gathered}
$$

World oil price

$$
\begin{aligned}
& r p_{t}^{\text {woil }}=p_{t}^{\text {woil }}-c p i_{t}^{*} \\
& \widehat{r p}_{t}^{\text {woil }}=r p_{t}^{\text {woil }}-\overline{r p}_{t}^{\text {woil }} \\
& \widehat{r p}_{t}^{\text {woil }}=\rho^{\widehat{r p p}^{\text {woil }}} \cdot \widehat{r p}_{t-1}^{\text {woil }}+\varepsilon_{t}^{\widehat{r p}^{\text {woil }}} \\
& \Delta \overline{r p}_{t}^{\text {woil }}=\rho^{\Delta \overline{r p}^{\text {woil }}} \Delta \overline{r p}_{t-1}^{\text {woil }}+\left(1-\rho^{\Delta \overline{r p}^{\text {woil }}}\right) \Delta \overline{r p}_{s S}^{\text {woil }}+\varepsilon_{t}^{\Delta \overline{r p}^{\text {woil }}}
\end{aligned}
$$

World food price

$$
\begin{gathered}
r p_{t}^{w f o o d}=p_{t}^{w f o o d}-c p i_{t}^{*} \\
\widehat{r p}_{t}^{w f o o d}=r p_{t}^{w f o o d}-\overline{r p}_{t}^{w \text { food }} \\
\widehat{r p}_{t}^{w f o o d}=\rho^{\widehat{r p}^{w f o o d}} \cdot \widehat{r p}_{t-1}^{w f o o d}+\widehat{\varepsilon}_{t}^{\widehat{r p}^{w f o o d}} \\
\Delta \overline{r p}_{t}^{w f o o d}=\rho^{\Delta \overline{r p}^{w f o o d}} \cdot \Delta \overline{r p}_{t-1}^{w f o o d}+\left(1-\rho^{\Delta \overline{r p}^{w f o o d}}\right) \Delta \overline{r p}_{s s}^{w f o o d}+\varepsilon_{t}^{\Delta \overline{r p}^{w f o o d}}
\end{gathered}
$$

External sector

$$
\begin{gathered}
\pi_{t}^{*}=\rho^{\pi^{*}} \pi_{t-1}^{*}+\left(1-\rho^{\pi^{*}}\right) \bar{\pi}_{S S}^{*}+\varepsilon_{t}^{\pi^{*}} \\
\hat{y}^{*}=\rho^{y^{*}} \hat{y}_{t-1}^{*}+\varepsilon_{t}^{\hat{y}^{*}} \\
r_{t}^{*}=i_{t}^{*}-E_{t} \pi_{t+1}^{*} \\
i_{t}^{*}=\rho^{i^{*}} i_{t-1}^{*}+\left(1-\rho^{i^{*}}\right)\left(\bar{r}_{t}^{*}+\pi 4_{t}^{*}\right) \\
\hat{r}_{t}^{*}=r_{t}^{*}-\bar{r}_{t}^{*} \\
\bar{r}_{t}^{*}=\rho^{\bar{r}^{*}} \bar{r}_{t-1}^{*}+\left(1-\rho^{\bar{r}^{*}}\right) \bar{r}_{s S}^{*}+\varepsilon_{t}^{\bar{r}^{*}} \\
v i x_{t}=\rho^{v i x} v i x_{t-1}+\varepsilon_{t}^{v i x}
\end{gathered}
$$


APPENDIX C. Calibration of the Model Coefficients

\begin{tabular}{|c|c|c|c|}
\hline Coefficient & Value & Coefficient & Value \\
\hline \multicolumn{2}{|c|}{ Real GDP } & \multicolumn{2}{|c|}{ Real interest rate } \\
\hline$b_{1}$ & 0.6 & $\rho^{\bar{r}}$ & 0.8 \\
\hline$b_{2}$ & 0.2 & $\bar{r}_{S S}$ & 1 \\
\hline$b_{3}$ & 0.6 & \multicolumn{2}{|c|}{ Real exchange rate } \\
\hline$b_{4}$ & 0.7 & $\rho^{\Delta \bar{z}}$ & 0.8 \\
\hline$b_{5}$ & 0.5 & $\Delta \bar{Z}_{S S}$ & -1 \\
\hline$b_{6}$ & 0.25 & \multicolumn{2}{|c|}{ Equilibrium version of UIP } \\
\hline$\rho^{\Delta \bar{y}}$ & 0.8 & $\rho^{\text {prem }}$ & 0.5 \\
\hline$\Delta \bar{y}_{s S}$ & 5 & $\alpha^{\text {prem }}$ & 0.5 \\
\hline \multicolumn{2}{|c|}{ Inflation } & \multicolumn{2}{|c|}{ Deflator and Nominal GDP } \\
\hline$w^{c}$ & 0.425 & $\rho^{\Delta p y}$ & 0.25 \\
\hline$w^{F}$ & 0.14 & $\rho^{\varepsilon^{\Delta p y}}$ & 0.85 \\
\hline \multicolumn{2}{|c|}{ Inflation-Core inflation } & \multicolumn{2}{|c|}{ Relative prices } \\
\hline$a_{11}$ & 0.5 & $\rho^{\overline{r p} \bar{p}^{C}}$ & 0.75 \\
\hline$a_{21}$ & 0.4 & $\frac{r}{\Delta \bar{r} \bar{p}_{s s}^{C}}$ & -0.75 \\
\hline \multirow{2}{*}{\multicolumn{2}{|c|}{ Inflation - Food price inflation }} & $\rho^{\overline{r p^{F}}}$ & 0.75 \\
\hline & & $\Delta \overline{r p} \bar{p}_{S S}^{F}$ & 0.75 \\
\hline$a_{12}$ & 0.5 & \multicolumn{2}{|c|}{ World oil price } \\
\hline$a_{22}$ & 0.2 & $\rho^{\widehat{r p p}^{\text {woil }}}$ & 0.7 \\
\hline$a_{32}$ & 0.25 & $\rho^{\Delta \overline{r p} \bar{w}^{\text {woil }}}$ & 0.85 \\
\hline \multicolumn{2}{|c|}{ Inflation - Energy price inflation } & $\overline{\Delta r p_{S S}^{\text {woil }}}$ & 5 \\
\hline$a_{13}$ & 0.5 & \multicolumn{2}{|c|}{ World food price } \\
\hline$a_{23}$ & 0.05 & $\rho^{\widehat{r p p}^{w f o o d}}$ & 0.7 \\
\hline \multicolumn{2}{|c|}{ Exchange rate } & $\rho^{\Delta \overline{r p}^{\text {woil }}}$ & 0.85 \\
\hline$e_{1}$ & 0.45 & $\Delta \overline{r p}_{s s}^{w \text { food }}$ & 0 \\
\hline \multicolumn{2}{|c|}{ Monetary policy: Interest rate } & \multicolumn{2}{|c|}{ External sector } \\
\hline$g_{1}$ & 0.75 & $\rho^{\pi^{*}}$ & 0.8 \\
\hline$g_{2}$ & 0.5 & $\bar{\pi}_{S S}^{*}$ & 2 \\
\hline$g_{3}$ & 0.2 & $\rho^{i^{*}}$ & 0.8 \\
\hline \multicolumn{2}{|c|}{ Credit Cycle and Lending Rate } & $\rho^{\hat{y}^{*}}$ & 0.8 \\
\hline$\rho^{\widehat{n c r}}$ & 0.5 & $\rho^{\bar{r}^{*}}$ & 0.9 \\
\hline$\alpha_{1}^{\widehat{\widehat{c} \widehat{r}}}$ & 0.14 & $\bar{r}_{S S}^{*}$ & 1 \\
\hline$\alpha_{1}^{\widehat{\widehat{C C} r}}$ & 0.12 & $\rho^{\text {vix }}$ & 0.25 \\
\hline$\rho^{\overline{n c r}}$ & 0.75 & \multicolumn{2}{|c|}{ Exports and Imports } \\
\hline$\Delta \overline{n c r} s s$ & 0 & $\rho^{\bar{x}}$ & 0.85 \\
\hline$\rho^{r s^{1 y}}$ & 0.75 & $\bar{x}_{s S}$ & 35 \\
\hline prem $^{T E R M}$ & 2.75 & $\rho^{\bar{m}}$ & 0.85 \\
\hline$\rho^{\text {prem }}$ & 0.8 & $\bar{m}_{s S}$ & 40 \\
\hline$\alpha^{\text {prem }^{c}}$ & 0.2 & $\rho^{\hat{x}}$ & 0.5 \\
\hline$\beta^{\text {prem }^{c}}$ & 0.001 & $\alpha^{x z}$ & 0.25 \\
\hline \multicolumn{2}{|c|}{ Macroprudential Policy Block } & $\alpha^{x y}$ & 0.6 \\
\hline ta $a^{\text {wedge }}$ & 30 & $\rho^{\widehat{m}}$ & 0.75 \\
\hline$\rho^{b c^{T A R}}$ & 0.975 & $\alpha^{m z}$ & 0.1 \\
\hline$b c_{S S}^{T A R}$ & 11 & $\alpha^{m y}$ & 0.4 \\
\hline$\phi$ & 0.5 & $\alpha^{\text {moil }}$ & 0.005 \\
\hline
\end{tabular}




\section{APPENDIX D. Identification and Bayesian Estimation}

\section{We test identification of selected parameters computing Fisher matrix and conducting its} SVD decomposition. Table A.1 reports normalized base vectors to judge about groups of parameters which can be identified together. Each column of the table represents one group where non-zero numbers indicate the parameters which can be identified in the particular group. Zeros indicates weak identification of the particular parameter. The closer are numbers to one respective closer to zero, the better is the identification respective worse. Columns are ordered starting from the best group to the worst. For further details see Andrle (2010) and Van den Hof et al. (2009).

The analysis suggests that parameters $\rho_{1}, \alpha_{1}, \alpha_{2}, \rho_{4}$, and $\alpha_{3}$ can be estimated together while in the case of other parameters we might face weak identification. ${ }^{53}$ In particular, it is the case of $\rho_{4}$ and $b_{5}$ parameters.

Table A.1: Normalized base vectors - SVD decomposition of Fisher matrix

\begin{tabular}{|c|c|c|c|c|c|c|c|c|c|c|c|c|}
\hline Parameter & 1. & 2. & 3. & 4. & 5. & 6. & 7. & 8. & 9. & 10. & 11. & 12. \\
\hline$b_{1}$ & 0.0 & -0.2 & 0.8 & 0.2 & 0.0 & 0.4 & -0.2 & 0.3 & -0.1 & 0.1 & 0.0 & -0.1 \\
\hline$b_{2}$ & 0.0 & -1.0 & -0.1 & 0.1 & 0.1 & 0.0 & 0.1 & -0.1 & 0.0 & 0.0 & 0.0 & 0.0 \\
\hline$b_{3}$ & 0.0 & 0.1 & 0.4 & 0.1 & 0.0 & 0.0 & 0.4 & -0.8 & 0.2 & -0.1 & 0.0 & 0.0 \\
\hline$b_{4}$ & 0.0 & -0.1 & 0.3 & 0.0 & 0.0 & -0.9 & 0.0 & 0.1 & 0.0 & 0.0 & 0.0 & 0.0 \\
\hline$b_{5}$ & 0.0 & 0.0 & -0.1 & 0.0 & 0.0 & 0.0 & 0.0 & 0.0 & 0.1 & 0.0 & 0.0 & -1.0 \\
\hline$b_{6}$ & 0.0 & 0.0 & 0.0 & 0.0 & 0.0 & 0.0 & -0.9 & -0.5 & 0.1 & 0.0 & 0.1 & 0.0 \\
\hline$\rho_{1}$ & 0.0 & 0.0 & -0.1 & 0.2 & 0.0 & -0.1 & 0.1 & -0.1 & 0.1 & 0.9 & 0.2 & 0.0 \\
\hline$\alpha_{1}$ & 0.0 & 0.1 & -0.2 & 0.9 & 0.0 & 0.0 & -0.1 & 0.1 & 0.0 & -0.2 & 0.0 & 0.0 \\
\hline$\alpha_{2}$ & 0.0 & 0.0 & 0.0 & 0.1 & 0.0 & 0.0 & 0.0 & -0.1 & 0.0 & 0.2 & -1.0 & 0.0 \\
\hline$\rho_{4}$ & 0.0 & 0.0 & 0.0 & 0.0 & -0.7 & 0.1 & 0.0 & 0.2 & 0.7 & -0.1 & 0.0 & 0.0 \\
\hline$\alpha_{3}$ & 0.0 & 0.0 & 0.0 & 0.0 & -0.7 & 0.0 & 0.0 & -0.1 & -0.7 & 0.1 & 0.0 & 0.0 \\
\hline$\alpha_{4}$ & 1.0 & 0.0 & 0.0 & 0.0 & 0.0 & 0.0 & 0.0 & 0.0 & 0.0 & 0.0 & 0.0 & 0.0 \\
\hline
\end{tabular}

Finally, we conducted Bayesian estimation of selected model parameters selected above. The parameters are estimated along with the variance of structural shocks in the respective equations. The posterior distribution is generated using Metropolis-Hasting algorithm with 100 thousand draws. The whole sample of the data was not used, only the period of 2008-2019. It seems that dynamics of financial variables has changed in the wake of world financial crisis. Figure A.1 and A2. present outcomes of estimation in the form of posterior distributions. Also, the prior and its values are clear from the Figures. For persistency parameters beta distribution is chosen, standard deviations of shocks are assumed to have inverse gamma distribution, and other parameters experience gaussian distribution.

\footnotetext{
${ }^{53}$ The selected group of parameters is the largest group available and at the same time it covers the most of parameters in the new credit and bank blocks, see column 10 of Table A.1. Option in column 8 was not selected as it encompasses also $b_{6}$ which is in the output gap equation and it covers the feedback from the credit to business cycles.
} 


\section{Figure A.1: Distribution of estimated parameters}

Note: Blue dotted line - prior, yellow line - posterior distribution, red line with circle - mode of the posterior, magenta with triangles parameter bounds
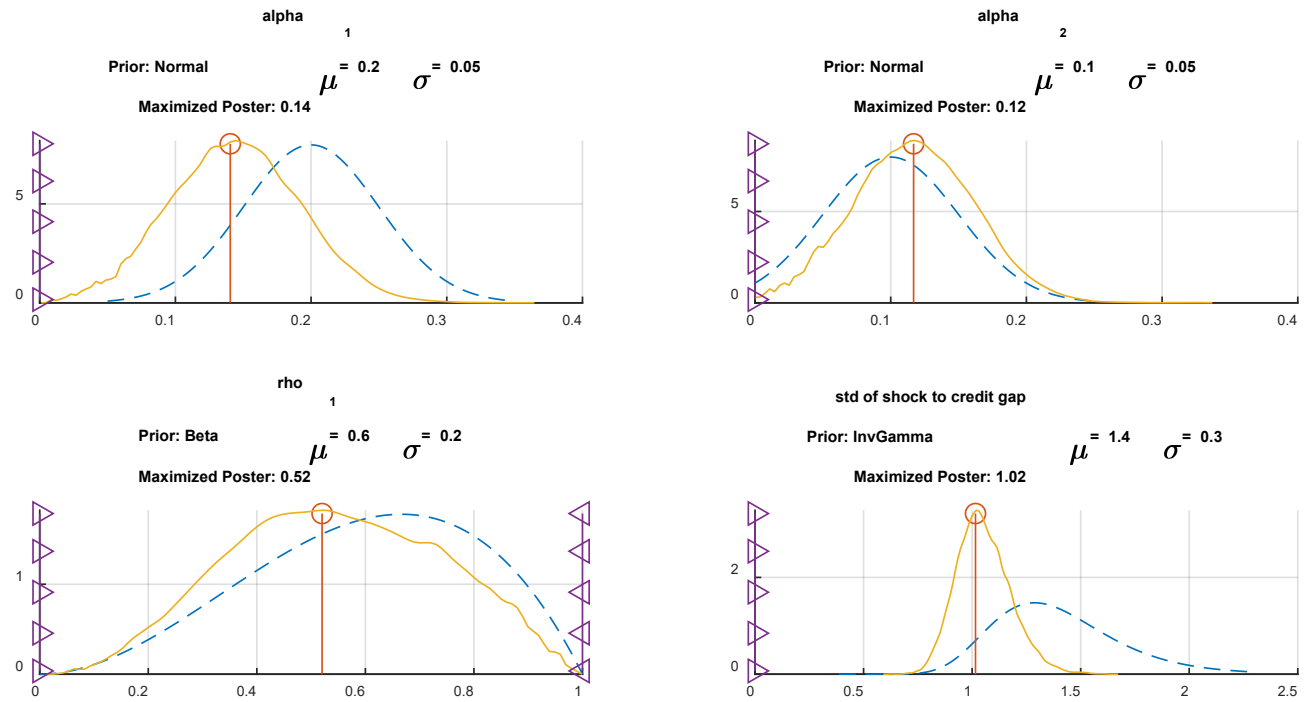

Source: Authors' computation

\section{Figure A.2: Distribution of estimated parameters}

Note: Blue dotted line - prior, yellow line - posterior distribution, red line with circle - mode of the posterior, magenta with triangles parameter bounds
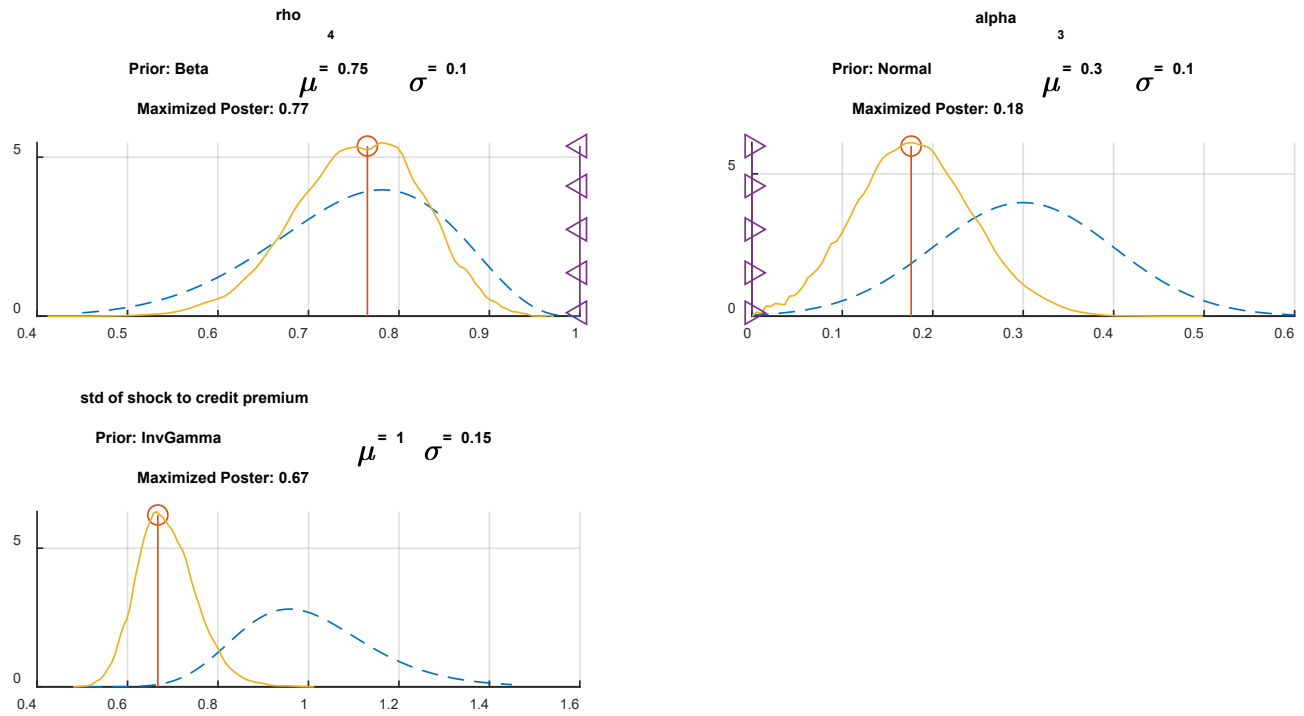

Source: Authors' computation 